\title{
Cholinergic Basal Forebrain Transplants Restore Diminished Metabolic Activity in the Somatosensory Cortex of Rats with Acetylcholine Depletion
}

\author{
S. Essie Jacobs, ${ }^{1}$ Alan Fine, ${ }^{3}$ and Sharon L. Juliano ${ }^{1,2}$ \\ 'Department of Anatomy and Cell Biology and ${ }^{2}$ Program of Neuroscience, Uniformed Services University of the Health \\ Sciences, Bethesda, Maryland 20814, and ${ }^{3}$ Department of Physiology and Biophysics, Dalhousie University School of \\ Medicine, Halifax, Nova Scotia, Canada B3H 4H7
}

It has been known for several years that stimulus-evoked metabolic activity is reduced in the somatosensory cortex of animals with basal forebrain lesions that deplete the neocortex of acetylcholine (ACh). During 2-deoxyglucose (2-DG) experiments, animals with unilateral basal forebrain lesions demonstrate a decreased response to somatic stimulation, while background metabolic activity in the surrounding cortical regions remains normal. In an attempt to ameliorate these deficits, we examined the ability of embryonic cholinergic basal forebrain transplants inserted into neocortex to innervate surrounding cortical regions and restore functional 2-DG activity in adult host rats previously depleted of $A C h$ by basal forebrain lesions. To accomplish this goal, a series of experiments were conducted in which we (1) depleted the cerebral cortex of $\mathrm{ACh}$ by injecting an excitotoxin into the rat basal forebrain, (2) transplanted embryonic basal forebrain or embryonic neocortical (control) tissue into the ACh-depleted cortex and, (3) 6-12 months later, used the 2-DG metabolic mapping technique to examine effects of the transplants on metabolic activity evoked by whisker stimulation in rat somatosensory (barrel) cortex. Histochemical analysis revealed that acetylcholinesterase (AChE) staining within $2 \mathrm{~mm}$ of the basal forebrain transplants was similar in density to the contralateral normal hemisphere. AChE staining farther than $2 \mathrm{~mm}$ from the basal forebrain transplants and throughout hemispheres containing neocortical (control) transplants was greatly reduced, with few AChEpositive fibers present, a finding typical of cerebral cortex in basal forebrain-lesioned animals. Stimulus-evoked 2-DG uptake in barrels adjacent to the basal forebrain transplants, and therefore within AChE-rich territory, was similar to that in corresponding barrels identically activated in the contralateral hemisphere. 2-DG activity was reduced, however, in

\footnotetext{
Received Mar. 29, 1993; revised July 19, 1993; accepted July 26, 1993.

This work was supported by R07064 (S.L.J.). We are grateful to Drs. Ramana Sonty and Marina Volkov for advice on statistical methods and to Don Eslin for technical assistance. We also thank Drs. Asaf Keller, Katy Lynch, Linda Porter, and Tim Pons for comments on an earlier version of the manuscript. We finally thank Dr. Marc Peschanski for important early discussions on this project. This work has been presented by S.E.J. in partial fulfillment of the requirements for the degree of Doctor of Philosophy at USUHS, Department of Anatomy and Cell Biology.

Correspondence should be addressed to Dr. Sharon L. Juliano, Department of Anatomy and Cell Biology, Uniformed Services University of the Health Sciences, 4301 Jones Bridge Road, Bethesda, MD 20814.

Copyright (C) 1994 Society for Neuroscience $0270-6474 / 94 / 140697-15 \$ 05.00 / 0$
}

stimulated barrels outside the region of dense AChE-positive staining, as well as in all activated barrels in hemispheres containing control transplants of embryonic neocortex. These results indicate that transplantation of cell suspensions containing embryonic cholinergic basal forebrain, but not neocortex, can ameliorate basal forebrain lesion-induced deficits in functional activity, and that the restoration of activity is influenced by proximity to the transplant.

[Key words: AChE, barrel, cytochrome oxidase, plasticity, 2-deoxyglucose, vibrissal

It is well established that basal forebrain lesions lead to cortical depletion of acetylcholine (ACh) (e.g., Johnston et al., 1979; Wenk et al., 1980). In an earlier series of experiments we found that unilatcral basal forcbrain lesions resulted in decreased cortical metabolic uptake in response to stimulation (Ma et al., 1989; Juliano et al., 1990; Jacobs et al., 1991). Using the 2-deoxyglucose (2-DG) technique we demonstrated that activity evoked by whisker stimulation in somatosensory cortex of rats and mice was reduced in dimension and intensity after unilateral basal forebrain lesions. In these studies, the 2-DG uptake was compared to similarly evoked activity in the opposite normal hemisphere; comparable results were found after unilateral basal forebrain lesions in other species (Juliano et al., 1990). In all previous investigations, background levels of metabolic label remained unchanged and the $2-D G$ reductions were particularly associated with evoked activity. These and many other recent studies emphasize the importance of $\mathrm{ACh}$ in normal cortical function, particularly in relation to processing of stimuli (Metherate et al., 1987, 1988a; Lamour et al., 1988; Rasmusson and Dykes, 1988). $\Lambda$ lthough $\Lambda \mathrm{Ch}$ has long been known to play a role in neocortical neuronal activity (Krnjević et al., 1971; Brown, 1983; McCormick and Prince, 1985), more recent experiments emphasize the significance of cholinergic involvement in enhancing neuronal responses to stimulation (Sillito and Kemp, 1983; Donoghue and Carroll, 1987; Sato et al., 1987; Sillito and Murphy, 1987; Lamour et al., 1988; Metherate et al., 1988b; McKenna et al., 1989; Metherate and Weinberger, 1989, 1990).

Current advances in the technique of transplantation suggest that implants of cholinergic tissue restore reductions in electrophysiological and metabolic activity in ACh-depleted hippocampus (Low et al., 1982; Kelly et al., 1985; Buzsáki et al., 1987; Vanderwolf et al., 1990). Studies by Fine et al. (1985a,b) and Dunnett et al. (1985) reveal the capacity of cholinergic transplants to survive and reinnervate previously ACh-depleted frontoparietal cortex. Furthermore, ACh-rich basal forebrain 
transplants placed into the neocortex lead to improved performance in learning and memory tasks. For example, basal forebrain-lesioned rats demonstrated improvement in tasks of response retention and spatial learning (such as passive avoidance and water maze learning) with transplants of cholinergic-rich basal forebrain tissue, but not with noncholinergic hippocampal tissue (Dunnett et al., 1985; Fine et al., 1985a,b). These results have subsequently been confirmed by others, demonstrating improved performance on spatial learning tasks with transplants of cholinergic basal forebrain, but not noncholinergic control transplants, in ACh-depleted cortex or hippocampus of rats (Arendt et al., 1989; Hodges et al., 1990). More recently, these results have been extended to primates, demonstrating that cholinergic basal forebrain tissue, but not control hippocampal tissue, grafted to the hippocampus of marmoset monkeys can completely reverse profound and specific learning disabilities resulting from fornix transection (Ridley et al., 1991, 1992). The precise placement of fetal tissue grafts as well as their source appear to increase dramatically their potential to restore function. Transplants of embryonic cholinergic basal forebrain tissue placed into nontarget sites are without behavioral effect, while similar tissue implanted into cholinergically depleted cortex or hippocampus results in functional recovery (Hodges et al., 1990).

As a result of the encouraging findings regarding the possibility of neural transplants to thrive and grow in new environments, as well as to induce functional improvements, we conducted a study that made use of these experimental advances. The experiments described here explore the capacity of cholinergic basal forebrain grafts placed into neocortex to ameliorate the deficits in stimulus-evoked metabolic activity observed after unilateral basal forebrain lesions.

These results have been presented in abstract form (Jacobs et al., 1990).

\section{Materials and Methods}

The study presented here involved a sequence of experiments. We tested the ability of fetal ACh-rich basal forebrain transplants to restore functional activity in the somatosensory cortex of adult rats with previous basal forebrain lesions. The specific manipulations included (1) excitotoxic lesions of the basal forebrain that depleted the ipsilateral somatosensory cortex of $\mathrm{ACh}$, (2) transplantation of embryonic basal forebrain or neocortical tissue into the ACh-depleted cortex, (3) 2-DG experiments, during which the rat received whisker stimulation, and (4) tissue processing that included 2-DG autoradiography, staining for Nissl substance, cytochrome oxidase (CO) activity, and acetylcholinesterase (AChE) histochemistry. A total of 33 rats were used for this study. Only experiments successful in all four phases of this study were used for the data analysis $(n=14)$. Criteria for success are presented in Results for each of the manipulations.

\section{Basal forebrain lesions}

One week prior to transplantation of embryonic basal forebrain, SpragueDawley rats weighing $175-250 \mathrm{gm}$ received unilateral injections of ibotenic acid into the basal forebrain. Two sets of coordinates were used, both aimed at the major source of cholinergic innervation to the somatosensory cortex: the nucleus basalis magnocellularis (nbm), substantia innominata, and ventromedial globus pallidus (Johnston et al., 1981; Mesulam et al., 1983; Rye et al., 1984; Saper, 1984). For one set of injections, a small opening in the skull was made $4 \mathrm{~mm}$ anterior to bregma and $2.3 \mathrm{~mm}$ lateral from the midline as described by Jacobs et al. (1991). A Hamilton syringe was angled $35^{\circ}$ from vertical and $12^{\circ}$ laterally and advanced $8.0 \mathrm{~mm}$ deep to the dura, where $0.5 \mu$ l of ibotenic acid $(10 \mu \mathrm{g} / \mu \mathrm{l})$ was injected over $2 \mathrm{~min}$. The needle was then retracted to a depth of $7.0 \mathrm{~mm}$ and an additional $0.5 \mu \mathrm{l}$ of ibotenic acid injected. The second set of coordinates, previously described by Fine et al. (1985a), required two openings in the skull. One was $1.0 \mathrm{~mm}$ anterior to bregma and $2.6 \mathrm{~mm}$ lateral from midline. A Hamilton syringe was advanced
$7.3 \mathrm{~mm}$ deep and $0.5 \mu \mathrm{l}$ of ibotenic acid was injected. The other injection of $0.5 \mu \mathrm{l}$ of ibotenic acid was made $7.0 \mathrm{~mm}$ deep to an opening $0.2 \mathrm{~mm}$ anterior to bregma and $3.4 \mathrm{~mm}$ lateral from midline. For this set of injections, the incisor bar was set $5.0 \mathrm{~mm}$ above the interaural line.

\section{Transplantation}

One week after the basal forebrain lesion, 14 adult host rats used for the data analysis received a cell-suspension transplant, of either cholincrgic-rich cmbryonic basal forcbrain $(n=7)$ from 16-d-old gestational age rat fetuses or neocortical control tissue $(n=7)$ from 14-15-d-old gestational age rat fetuses, into the $\mathrm{ACh}$-depleted, ipsilateral frontoparietal cortex. The cell-suspension transplants were prepared as described previously (Björklund et al., 1983; Fine et al., 1985a). Briefly, using aseptic technique, fetuses were taken by cesarean section from the mother, and their brains removed and placed in a sterile, ice-cold solution of $0.6 \% \mathrm{D}$-glucose in saline. Either embryonic basal forebrain or pieces of the developing neocortex were dissected and incubated for $20 \mathrm{~min}$, at $37^{\circ} \mathrm{C}$, in $10 \mathrm{ml}$ of the D-glucose solution with $2.5 \mathrm{mg}$ trypsin (Sigma type XIII) added. The tissue was then rinsed in D-glucose solution containing DNase (Sigma DNase I; $1 \mathrm{mg} / 10 \mathrm{ml}$ ). The brain pieces were transferred to a vial in a final volume of $10 \mu \mathrm{l}$ of the DNase/D-glucose solution per brain, and gently dissociated using fire-polished Pasteur pipettes. Viability of the dissociated cells was evaluated using ethidium bromide exclusion before and after transplantation. For all the cell suspensions prepared, a greater than $80 \%$ viability was found both before and after the transplantation session.

Two microliters of cell suspension were injected into two sites in the frontoparietal cortex ipsilateral to the basal forebrain lesion. These sites were in close proximity to, or within, the portion of somatosensory cortex receiving input from the whiskers. One site was $0.3 \mathrm{~mm}$ posterior to bregma, $3.2 \mathrm{~mm}$ lateral to midline, and $2.5 \mathrm{~mm}$ deep from the dura. The second site was $2.3 \mathrm{~mm}$ posterior to bregma, $3.2 \mathrm{~mm}$ lateral to midline, and $2.5 \mathrm{~mm}$ deep from the dura. For all injections, the incisor har was set at $-3.3 \mathrm{~mm}$. The animals survived for 6-12 months. One week prior to a terminal 2-DG experiment, the rats received a repeat basal forebrain lesion as described above to reduce the possibility that cholinergic innervation of the cortex might result from remaining or restored connections from the basal forebrain.

\section{2-DG experiment}

Rats were anesthetized with halothane (1-2\%) and a jugular vein catheterized. Following this procedure, each rat was loosely restrained on a block where all but two to four whiskers were trimmed bilaterally and symmetrically, and a long-lasting topical anesthetic placed on the site of catheter insertion. The halothane was then removed and the rat allowed to recover from the anesthesia for $1.5 \mathrm{hr}$ prior to a pulse intravenous injection of 2-DG $\left(10 \mu \mathrm{Ci} / 100 \mathrm{gm}\right.$ of 2 -deoxy-D-[1- $\left.\left.{ }^{14} \mathrm{C}\right] \mathrm{glucose}\right)$.

The selection of the number and the location of specific whiskers for stimulation during the 2-DG experiment was based on several factors. (1) A number of whiskers were chosen (usually three) in order to increase the possibility of activating barrels in different proximity to the transplant. In each animal, we therefore attempted to activate barrels both close to and far from the transplanted tissue. (2) Whiskers were selected that were not adjacent to one another, but that could easily be stimulated simultaneously. (3) Matching whiskers on each side were always chosen.

The whiskers were stimulated manually using a hand-held brush. Stimulation of the whiskers began $5 \mathrm{~min}$ before the animal received the $2-D G$ injection and continued for $45 \mathrm{~min}$. Care was taken to ensure that both sides received identical stimulation during the $45 \mathrm{~min}$ period. The animal then received an overdose of sodium pentobarbital $(50 \mathrm{mg}$ $\mathrm{kg}$ ) and was perfused intracardially with saline, followed by $0.1 \mathrm{M}$ phosphate-buffered paraformaldehyde ( $4 \%$ ) with $4 \%$ sucrose added. The brain was quickly removed, frozen in Freon 22 , and stored in a freezer at $-70^{\circ} \mathrm{C}$ until cut.

\section{Tissue processing}

Using a cryostat at $-16^{\circ} \mathrm{C}, 30-\mu \mathrm{m}$-thick sections were cut in the coronal plane. Adjacent sections were saved for 2-DG autoradiography and AChE and CO histochemistry. Sections for 2-DG autoradiography were collected on slides coated with $2 \%$ gelatin and placed on a warming tray $\left(60^{\circ} \mathrm{C}\right)$ for rapid dehydration. The slides, along with ${ }^{14} \mathrm{C}$ methylacrylate standards, were exposed to x-ray film (SB-5, Kodak) in cassettes for approximately $7 \mathrm{~d}$. Sections for AChE histochemistry were also saved 

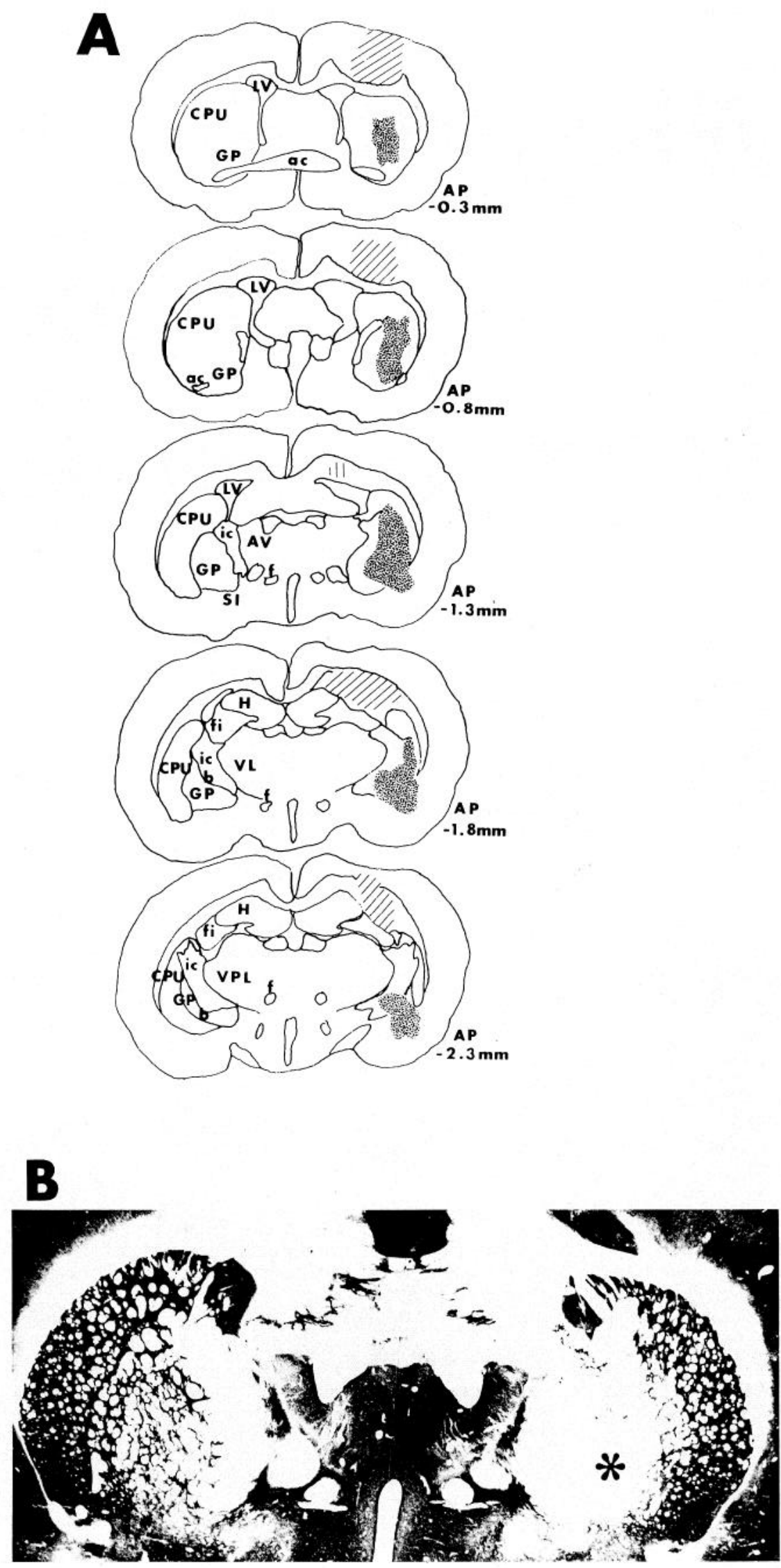

Figure 1. A typical lesion in the basal forebrain after injections of ibotenic acid. $A$, Drawings taken directly from the brain of a rat that received a lesion. The sections are in the coronal plane at representative rostrocaudal levels, illustrating the site of a lesion (dark shading). The lesions generally included the nucleus basalis magnocellularis $(b)$ and the ventromedial globus pallidus $(G P)$. The location of the transplant is indicated with hatched lines. The anteroposterior $(A P)$ levels are taken from Paxinos and Watson (1982). B, A section stained for $\mathrm{CO}$ activity demonstrating reduced staining at the site of the lesion (asterisk). ac, anterior commissure; $A V$, anteroventral nucleus of the thalamus; $C P U$, caudate-putamen; $f$, fornix; $f$, fimbria; $H$, hippocampus; $i c$, internal capsule; $L V$, lateral ventricle; $S I$, substantia innominata; $V L$, ventrolateral nucleus of the thalamus; $V P L$, ventroposterolateral nucleus of the thalamus. 

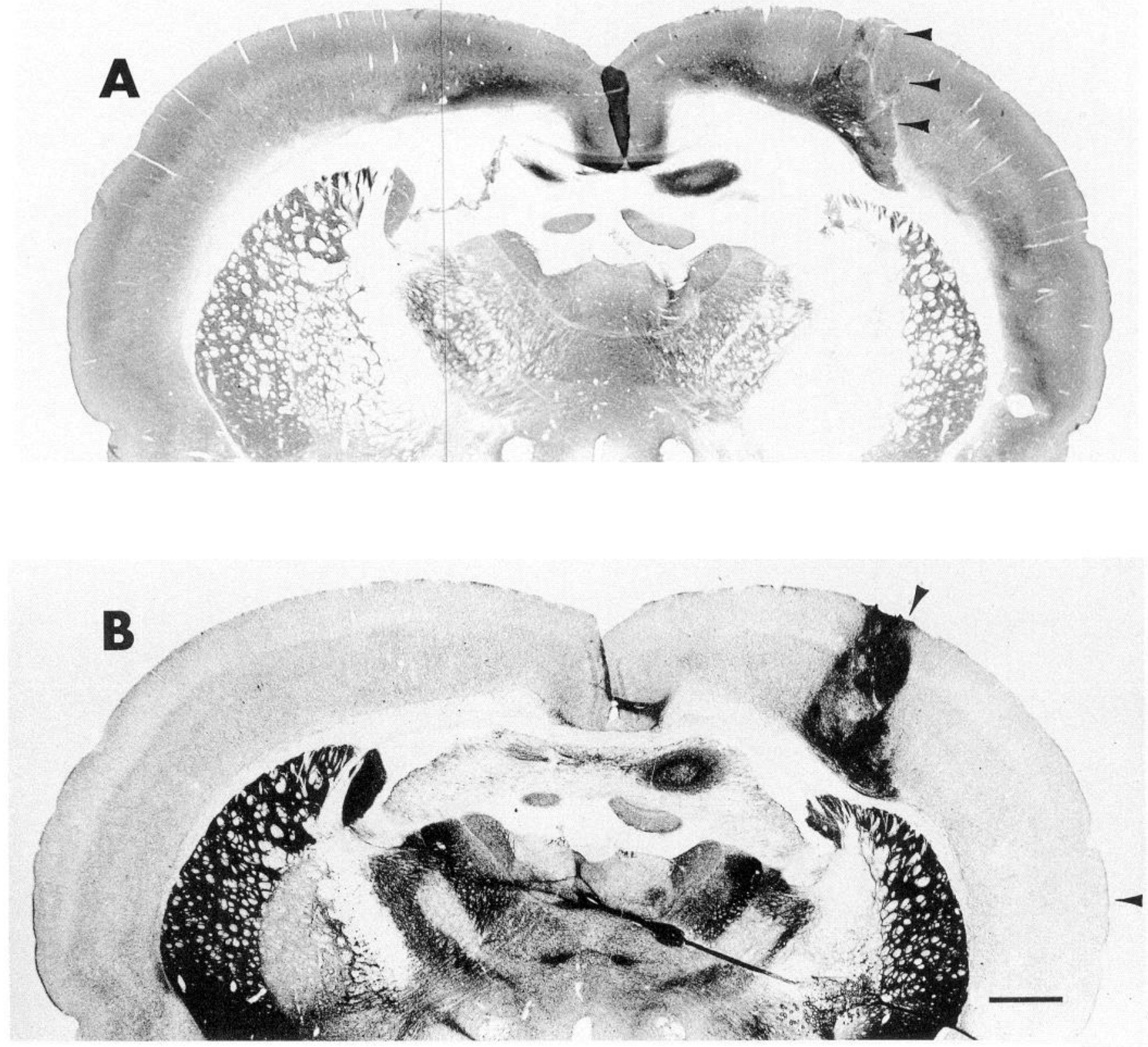

Figure 2. A, Photomicrograph of a coronal section through a rat brain that received a transplant of embryonic basal forebrain tissue. The arrowheads outline the lateral border of the transplant. The section is stained for $\mathrm{CO}$ activity; the staining intensity of the transplant is similar to that of the surrounding cortex. B. Photomicrograph of an adjacent section stained for AChE activity. Intense staining can be seen throughout the transplant. Close to the transplant the AChE staining intensity is relatively high; more laterally, density of the staining diminishes, due to a prior lesion of the basal forebrain. The arrowheads bound the region shown at higher power in $C$. The staining in the hemisphere on the left in both $A$ and $B$ represents a normal pattern. $C$ (facing page), A higher-power view of $B$ indicating that the density of AChE-stained fibers decreases with distance from the transplant. Scale bars, $1 \mathrm{~mm}$.

on gel-coated slides and processed using the method of Koelle (1955) as adapted by Jacobowitz and Creed (1983). Sections for CO histochemistry were processed according to Wong-Riley (1979).

\section{Data analysis}

Computer analysis of autoradiographic images. Using a video-based image-processing system, with a PDP $11 / 23+$ host computer, the autoradiographs were displayed, digitized, and calibrated with reference to the ${ }^{14} \mathrm{C}$ standards. By converting the optical density values into either color or gray scales through the use of look-up tables, we were able to quantify variability in the $2-\mathrm{DG}$ label within individual sections.
Measurements of metabolic activity associated with the activated barrels were obtained from the individual autoradiographs. Regions of cortex surrounding the activated barrels, but not receiving specific stimulation, were also measured. The optical density values were expressed as a percentage above background (background was considered to be the optical density of white matter).

Two-dimensional maps of the frontoparietal cortex were generated from autoradiographs every $100 \mu \mathrm{m}$ in the coronal plane, using software that partitions a designated area of cortex into vertical and tangential arrays of high resolution. In this computerized analysis, layer IV of the selected region of cortex was indicated using a digitizing tablet. Vertical bins were generated in the region of interest, of approximately $50 \mu \mathrm{m}$ 


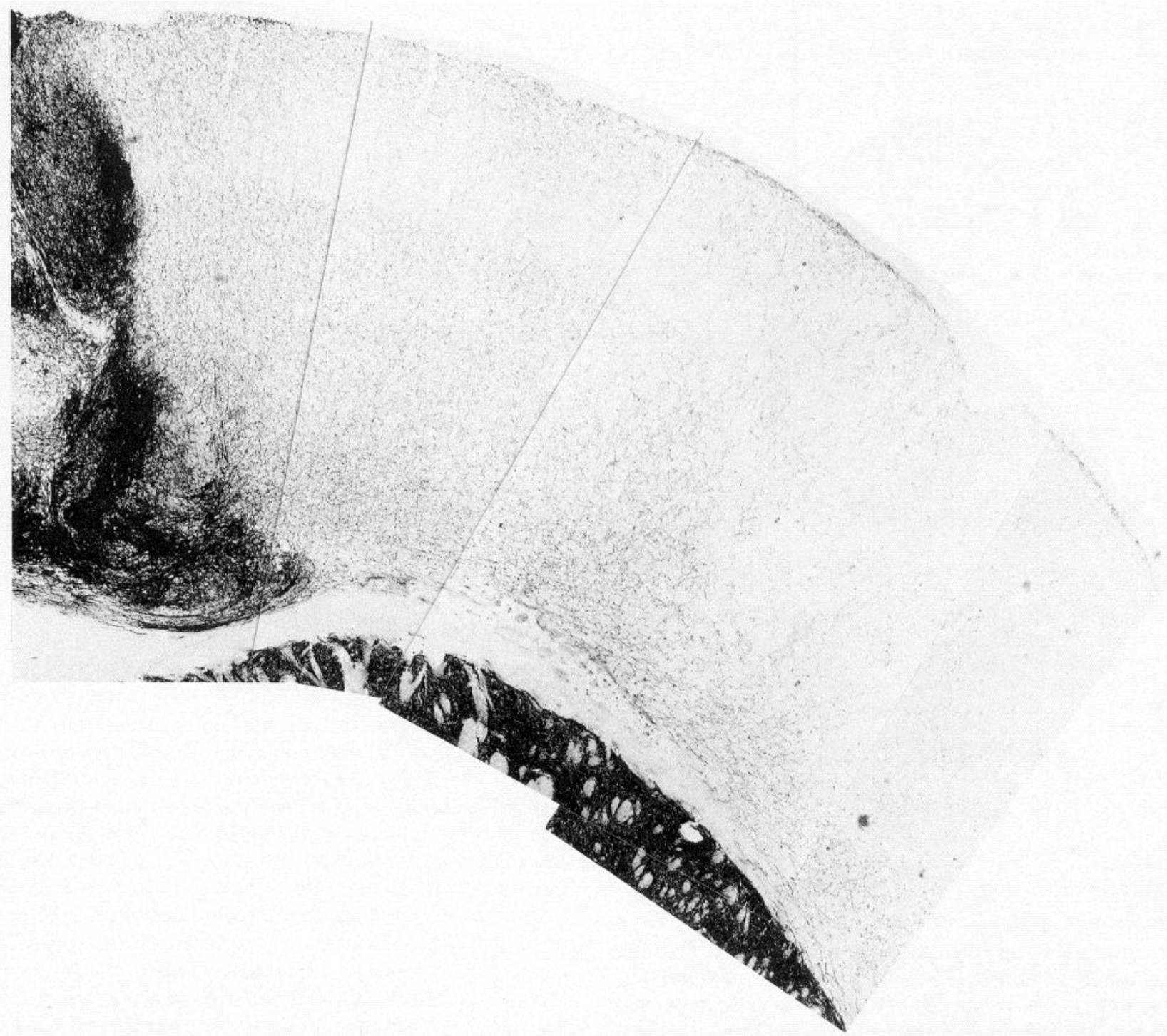

width, which contained the average density values from layers II-V. The files containing the density information were then aligned and displayed as digitized maps of activity in flattened somatosensory cortex, thus visualizing an average density through layers II-V (Tommerdahl et al., 1985). Both sides of the brain were digitized together, under the same conditions, to ensure that both hemispheres would be treated equally.

Specific loci of high activity emerged within the posteromedial barrel subfield (PMBSF), reflecting 2-DG uptake in the barrels. To determine the area of increased activity associated with the barrels, we obtained the average pixel intensity for the entire two-dimensional map of each hemisphere, and measured areas whose pixel value was 2 standard deviations (SDs) or more above the average intensity. This thresholding allowed regions of increased activity to emerge that always corresponded with barrel-associated spots (e.g., see Fig. 6). In all of our analyses the spots of label on the autoradiographs were compared with adjacent $\mathrm{CO}$ stained sections and the Nissl staining in order to verify the presence of a "barrel." The areas that emerged with our thresholding, therefore, were known to correspond to a cytoarchitectonic "barrel." These highdensity regions were measured using a digitizing tablet and customdesigned software. Although the barrel-associated spots usually appeared as a single focus of label, occasionally small ectopic foci also fell into the 2 SD thresholded range. In these cases, if the ectopic foci were in the territory of the "barrel" (as determined on adjacent CO sections) it was included in the measurement; if it lay outside the cytoarchitectonic barrel, it was excluded from the measurement. The resulting areal dimensions of these regions allowed us to compare corresponding barrelassociated spots in the normal and transplanted hemispheres, since matching whiskers were always stimulated during the 2-DG experiment (see Figs. 10-12). 2-DG uptake in barrels at various distances from the transplants was determined.

Computer analysis of $A C h E$ innervation. The number of AChE-stained fibers was counted in both hemispheres of three rats using the method described by Stichel and Singer (1987). The optical density of AChE staining was measured for these same six hemispheres using the imageanalysis system; a linear relationship was observed between the fiber counts and the optical density measurements. The optical density values in the AChE sections, as related to the fiber densities, allowed us to determine the amount of depletion (expressed as a percentage of levels in the identical region of the opposite, unlesioned hemisphere) at various distances from the transplant, following the basal forebrain lesion. The optical density measurements also allowed for quantification of the amount of AChE innervation after basal forebrain lesions, as well as an objective measurement of reinnervation following transplants of basal forebrain tissue. Measurements of the optical density of AChE-stained fibers were taken through several trajectories perpendicular to the pial surface. One trajectory was measured in the normal hemisphere that traversed a path through one of the activated barrels. A number of 
Figure 3. Histograms representing the density of AChE staining in an animal with a unilateral basal forebrain lesion that received an embryonic basal forebrain transplant. See Results for details. Each curve in the histogram represents density values taken through a path in the cortex at location $A, B, C$, or $D . A$ is taken through the transplant itself (hatched region), and thus is relatively high in intensity; $B$ is taken through the normal hemisphere; $C$ represents a path through a sector within $2 \mathrm{~mm}$ of the transplant, that is, within the territory containing AChE density at least $85 \%$ of normal; $D$ represents a path farther from the transplant, with decreased intensity of staining. For purposes of this histogram, the optical density values are represented on a scale from 0 to 255 , with 0 the least dense and 255 the most dense. The distance of each trajectory through the cortex from the pial surface is indicated on the $x$-axis. The location of the lesion in this animal is indicated with shading.

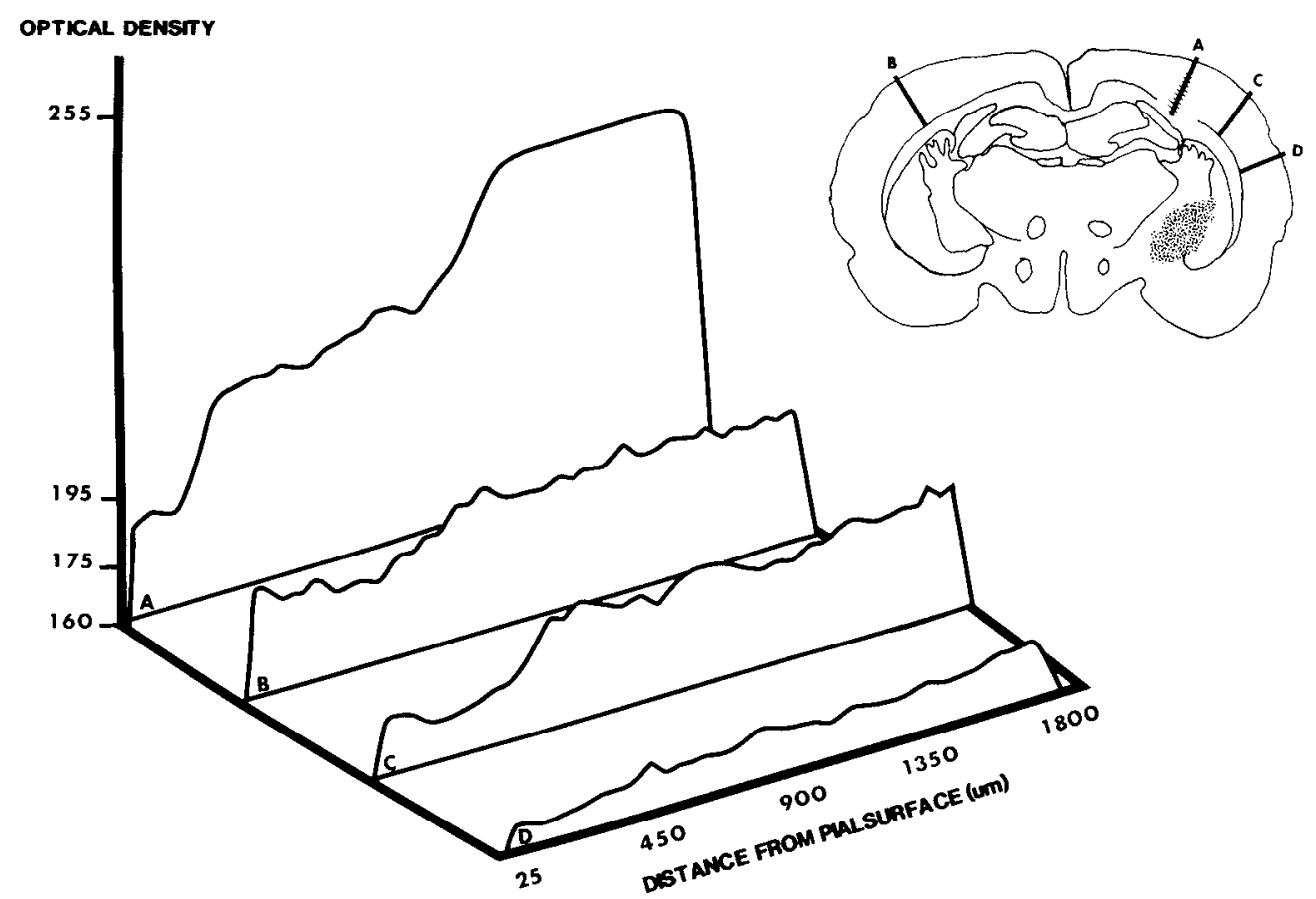

different sites were selected in the transplanted hemisphere that included the transplant itself, each region of cortex that contained a barrel activated during the 2-DG experiment (as identified on adjacent 2-DG autoradiographs), and a path through a cortical site relatively distant from the transplant that had not been specifically activated during the 2-DG experiment. The numerical values of the optical densities in the path of cach trajectory allowed us to generate histograms reflecting AChE density (see Figs. 3, 5).

\section{Results}

\section{Basal forebrain lesion and consequent $A C h$ depletion}

The primary tool used to assess the placement of each basal forebrain lesion was the pattern of staining for $\mathrm{CO}$ activity, which has previously been shown to be a reliable marker delineating excitutoxic lesion sites (Ma et al., 1989; Juliano et al., 1990 ). Figure $1 A$ is a drawing of a typical lesion site encompassing the ventromedial globus pallidus, the $\mathrm{nbm}$, and the substantia innominata. Figure $1 B$ is a section stained for $\mathrm{CO}$ activity, which also indicates the site of the lesion. Each lesion was carefully assessed to exclude cases from further analysis where the lesion damaged the thalamus, although we included two cases that had slight damage to rostral portions of the thalamic reticular nucleus. The extent of cortical cholinergic depletion was evident as a marked decrease in the density of AChE-stained fibers in the somatosensory cortex ipsilateral to the lesion, compared to the contralateral normal hemisphere. Experiments considered successful for this phase of the study included animals with lesions that (1) were within the designated boundaries, and (2) resulted in AChE-positive fiber staining in the experimental hemisphere that was no more than $40 \%$ of that in the opposite hemisphere, that is, a $60 \%$ depletion.

\section{Histologic assessment of the transplants}

Basal forebrain transplants. Figure $2 A$ demonstrates the appearance of $\mathrm{CO}$ staining in a rat that received a basal forebrain transplant. Within the transplant, regions of increased staining intensity, which correspond to cell-dense clusters, can be detected. Relative to the overall staining pattern in the cerebral cortex, however, the intensity of CO staining within the transplant is not grossly different from the surrounding cortex. While there are subtle variations in the appearance of the CO-stained transplants in different animals, the relative similarity of staining between cortex and transplant is a consistent finding.

AChE staining in the section adjacent to the CO-stained section seen in Figure $2 A$ is shown in Figure $2 B$. Basal forebrain cell-suspension transplants are easily recognizable due to their intense AChE staining. The AChE staining also exhibits fluctuations in density that correspond to cell-dense regions, identified on adjacent Nissl-stained sections. The density of AChEpositive fibers in cortex immediately adjacent to the transplant is increased compared to cortical regions lying farther from the transplant. An example is shown in Figure $2 C$, a higher-power photomicrograph of the cerebral cortex adjacent to the basal forebrain transplant shown in Figure $2 B$. A dense network of cholinergic fibers emanates from the transplant; in some cases, denser than the innervation in the contralateral, normally innervated hemisphere. Regions farther from the transplant are substantially reduced in AChE staining intensity. Fibers that emerge from the transplant into the deep cortical layers tend to run a horizontal course before turning toward the pial surface; those entering directly into supragranular layers tend to course diagonally as they ascend to the pial surface. In many instances, individual fibers in the surrounding cortex can be traced directly into the transplant. Although it is possible that these fibers do not originate directly from the cell suspension, the pattern of AChE staining surrounding the transplant suggests that the increase is most likely the result of innervation from the transplant. Similar patterns have been described previously (Fine et al., 1985a).

Using our image-analysis system, we compared the density of the AChE staining at specific sites in the transplanted hemisphere with the AChE density in the opposite untreated hemisphere (see Materials and Methods). Quantitative densitometry 

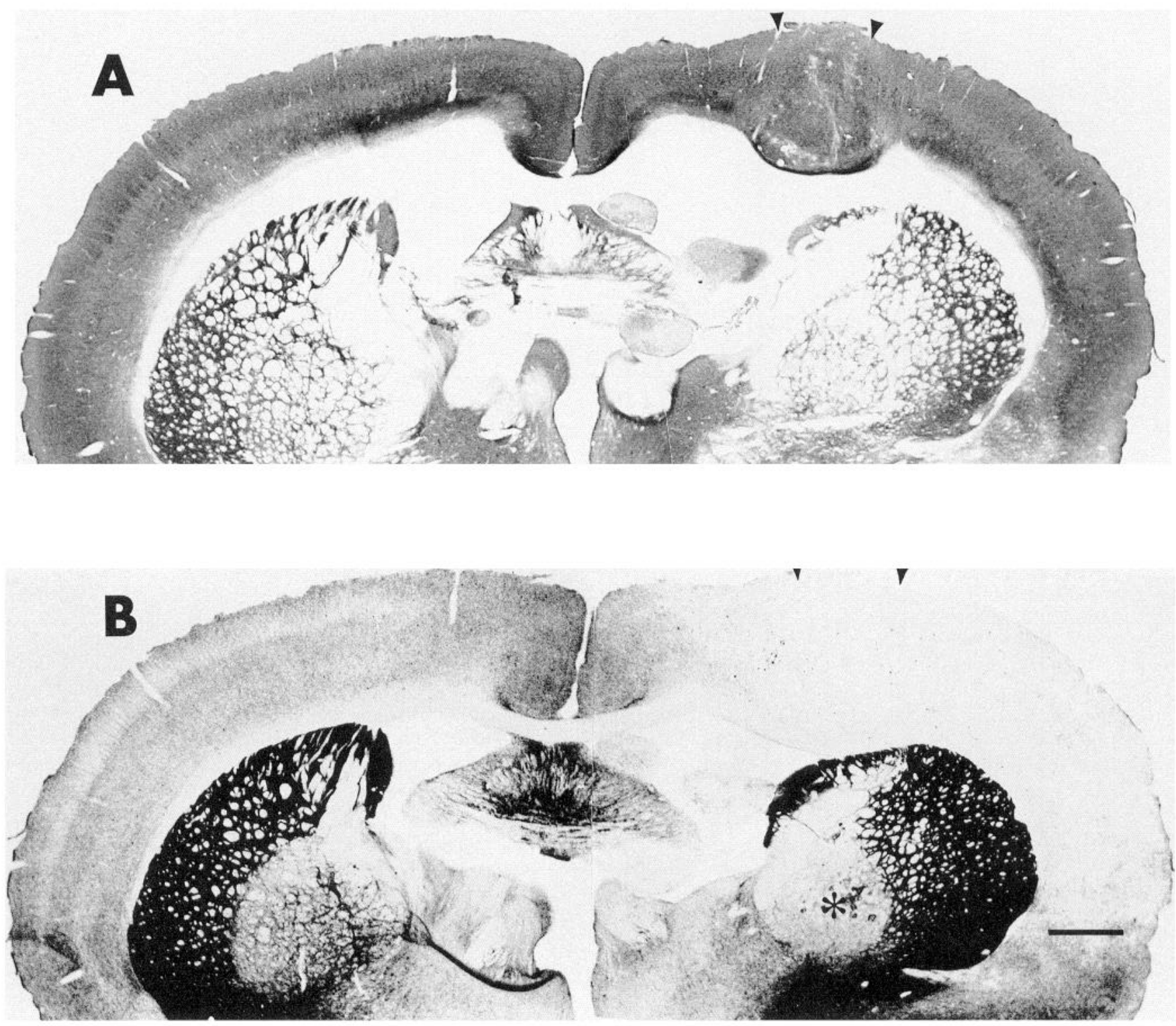

Figure 4. Adjacent sections in the coronal plane taken from a rat with a prior unilateral basal forebrain lesion that received a transplant of embryonic neocortex. Arrowheads bound the transplant. $A$, In this section, stained for $\mathrm{CO}$ activity, fluctuations in the density of staining are evident. $B$, Adjacent section reacted for AChE activity, demonstrating unilateral AChE depletion on the right. The transplant is barely visible using this type of stain. The site of the ibotenic acid lesion can be seen in the globus pallidus (asterisk). Scale bar, $1 \mathrm{~mm}$.

measurements of AChE staining included the transplant itself, all cortical regions that contained barrels activated by whisker stimulation during the 2-DG experiment, and a sector of cortex farther from the transplant not specifically activated during the 2-DG study. We determined these specific loci by comparing the AChE-stained sections with adjacent 2-DG autoradiographs. Figure 3 contains optical density histograms generated at specified sites in an AChE-stained section.

We found using this quantitative analysis that all the cortical regions studied fell into three groups: group A, cortical sites in animals that received a basal forebrain transplant and lay close to the transplant ( $\left.\mathrm{BF} \& \mathrm{AChE}^{+}\right)$; group $\mathrm{B}$, cortical sites in basal forebrain-transplanted rats that lay far from the transplant (BF \& $\mathrm{AChE}^{-}$); and group $\mathrm{C}$, cortical sites in animals receiving control (neocortical) transplants (Cortex \& $\mathrm{AChE}^{-}$).

For the group of animals receiving basal forebrain transplants,
(1) the optical density of AChE staining within $1.5 \mathrm{~mm}$ from the basal forebrain transplants was at least $85 \%$ that of the normal hemisphere, with dense AChE-positive fibers extending from the basal forebrain transplant. This is the $\mathrm{BF} \& \mathrm{AChE}^{+}$ group A. The extent of the apparent transplant-derived fiber outgrowth was independent of the size of the transplant. Between 1.5 and $2.0 \mathrm{~mm}$ from the transplant, optical density values varied considerably, from $35 \%$ to $92 \%$ of the contralateral hemisphere. (2) In cortical regions farther than $2 \mathrm{~mm}$ from the transplant, the AChE fiber density was $30-40 \%$ of normal. This is the BF \& $\mathrm{AChE}^{-}$group B.

Acceptable criteria for successful transplantation of both basal forebrain and neocortical tissue included visualization of apparently healthy cells, as revealed by Nissl staining and demonstration of robust staining for $\mathrm{CO}$ activity. In experiments involving basal forebrain transplants, intense staining for $\mathrm{AChE}$ 


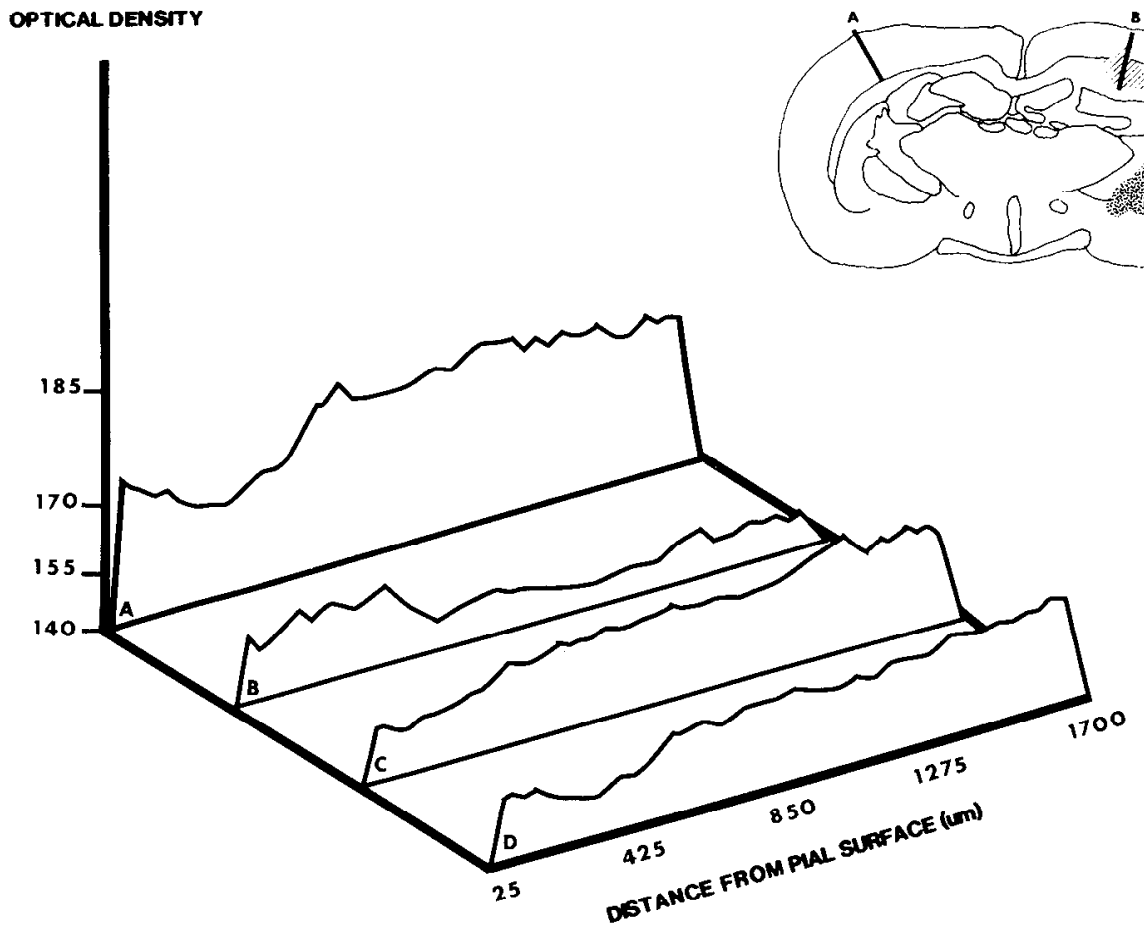

Figure 5. Histogram of the density of AChE staining in an animal that received a unilateral basal forebrain lesion (shading) and a transplant of embryonic cerebral cortex (hatched region). Each curve in the histogram represents $\mathrm{AChE}$ density values of trajectories that traversed the normal hemisphere $(A)$, the transplant $(B)$, a path within $2 \mathrm{~mm}$ of the transplant $(C)$, and a path relatively far from the transplant $(D)$. All the curves through the experimental hemisphere $(B, C$, and $D)$ are reduced in density from the normal side $(A)$. See Figure 3 and the text for details. was also a required component. We had very few transplants that were not well positioned, but a number of animals that received control cortical cell suspensions were rejected from consideration in this study because the transplants grew into the striatum and, in one instance, into the thalamus.

Neocortical (control) transplant. The appearance of a typical cell-suspension "control" transplant of embryonic neocortical
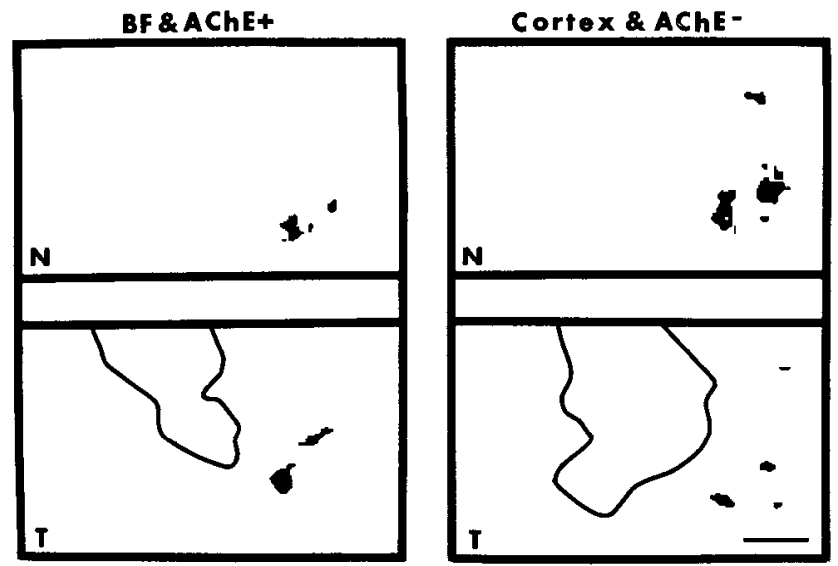

Figure 6. Examples of digitized two-dimensional maps of stimulusevoked metabolic activity that were visualized at a threshold 2 SDs above background (see Results for details). These maps correspond to Figures 7 and 14. The spots of label were related to the CO-stained sections to verify the presence of the appropriate barrel. Ectopic foci that appeared as a result of the threshold values were excluded from measurement if they lay outside the cytoarchitectonic barrel. $B F \&$ $A C h E^{+}$represents a map taken from an animal receiving a basal forebrain transplant, including the basal forebrain-lesioned and transplanted hemisphere $(T)$ and the normal, opposite hemisphere $(N)$. Cortex \& $A C h E^{-}$represents a map taken from an animal receiving a control, neocortical transplant, including the basal forebrain-lesioned and transplanted hemisphere $(T)$ and the normal, opposite hemisphere $(N)$. Solid lines bound the transplants. Scale bar, $1 \mathrm{~mm}$. tissue is shown in Figure 4. These transplants stain poorly for AChE (Fig. $4 B$ ), confirming the paucity of cholinergic elements. Sections stained for $\mathrm{CO}$ activity were used to confirm both the placement and robustness of the neocortical transplant (Fig. 4A). The distribution of $\mathrm{CO}$ activity is usually homogeneous and generally similar in appearance to the surrounding cortex, although in some animals areas of cell-dense clusters account for isolated patches of increased staining. After determining the borders of the cortical transplants, the AChE-stained sections were examined to determine whether staining varied systematically with distance from the transplant. There is no difference between the density of AChE staining observed adjacent to the transplant and that observed within the same hemisphere but farther from the transplant. (Thesc animals correspond to group $\mathrm{C}$ described above, Cortex \& $\mathrm{AChE}^{-}$.) The $\mathrm{AChE}$ staining pattern throughout the transplanted hemisphere is similar to that in animals with $\mathrm{AChE}$ depletion subsequent to basal forebrain lesions (Fine et al., 1985a; Ma et al., 1989; Jacobs et al., 1991). The AChE histochemistry in the opposite hemisphere appears normal.

A typical densitonetric analysis of AChE-stained fibers in the normal hemisphere and in the hemisphere containing the control graft is shown in Figure 5 (see Materials and Methods). The mean optical density values of AChE staining for all cortical sites ipsilateral to the neocortical transplants ranged from $25 \%$ to $40 \%$ of normal, both within the transplant itself and at varying distances.

\section{2-DG uptake}

Animals recciving cholinergic basal forcbrain transplants. The 2-DG uptake elicited by whisker stimulation was significantly decreased in AChE-depleted cortical territory, similar to results of previous studies (Ma et al., 1989; Jacobs et al., 1991). The average optical density of barrel-associated label relatively far from the transplant, and therefore in AChE-depleted cortex, was significantly different from matched counterparts in the opposite 

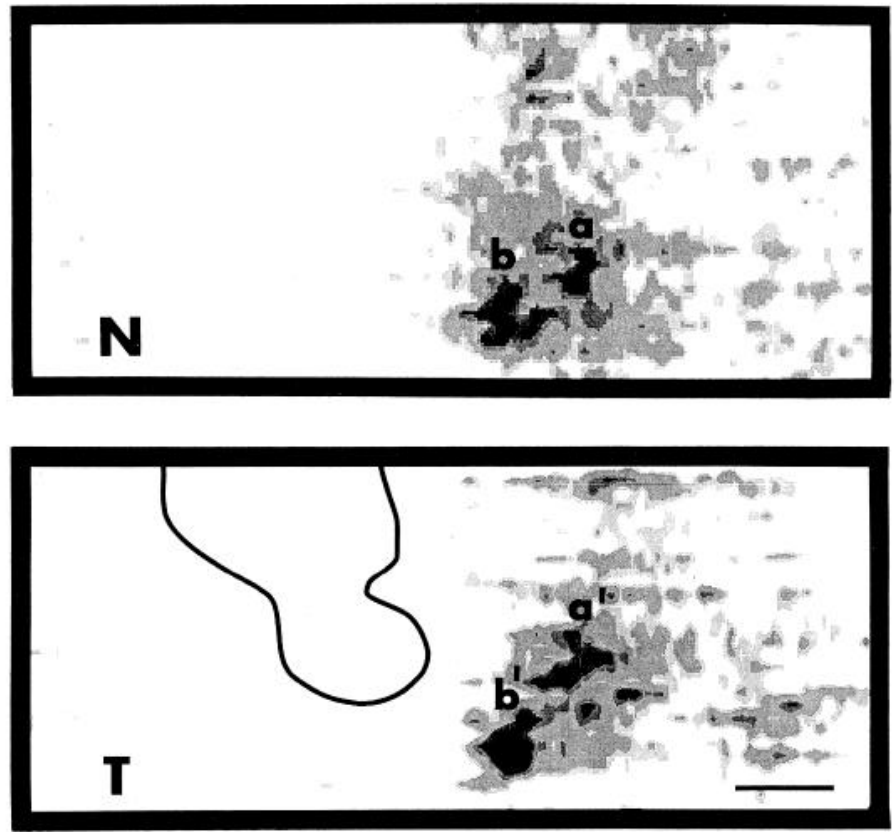

Figure 7. Two-dimensional maps of 2-DG activity through the somatosensory cortex of a rat that received a transplant of embryonic basal forebrain. Both hemispheres are shown, including the normal side $(N)$ and the experimental side $(T)$, which received a prior basal forebrain lesion and the transplant (location bounded with heavy black lines). During the 2-DG experiment, two whiskers were stimulated bilaterally (C3 and D1), which evoked two spots of barrel-associated label in the somatosensory cortex of both hemispheres (indicated on the maps as $a / a^{\prime}$ and $\left.b / b^{\prime}\right)$. Both spots of activity in the hemisphere receiving the transplant $\left(a^{\prime}\right.$ and $\left.b^{\prime}\right)$ are within $1.5 \mathrm{~mm}$ from the transplant, and similar in dimension to the spots of activity elicited in the normal hemisphere. The maps are normalized so that values $45 \%$ above the mean value of the entire map are visualized as light gray, values $55-60 \%$ above the mean are intermediate gray, and values $70 \%$ or greater than the mean are black. Values lower than $45 \%$ average are set to white. Medial is to the left; rostral is up. Scale bar, $1 \mathrm{~mm}$.

hemisphere (paired $t$ test, $p<0.05$ ). In contrast, 2-DG uptake in activated barrels close to the basal forebrain transplants, and within AChE-positive territory, was not significantly different from the opposite unlesioned hemisphere (Table 1).

The two-dimensional maps of metabolic activity allowed us to visualize 2-DG uptake evoked by whisker stimulation throughout somatosensory cortex. As indicated in the Materials and Methods, the maps were set to a threshold (densities greater than 2 SDs above the average), which we used to measure the areas of the whisker-evoked spots of label. Examples of the thresholded maps can be seen in Figure 6. In Figures 7 and 8, maps of the normal $(\mathrm{N})$ hemisphere and the hemisphere containing the transplant $(\mathrm{T})$ are shown; the boundaries of the transplant are indicated with heavy black lines. In both figures, companion spots of barrel-associated label are indicated ( $\mathrm{a}$ is matched with $\mathrm{a}^{\prime}$, b matched with $\mathrm{b}^{\prime}$, and so on). The barrel-associated spots in cortical territory close to basal forebrain transplants (i.e., within $1.5 \mathrm{~mm}$ ), with levels of AChE staining at least $85 \%$ of the opposite unlesioned side, are not significantly different in areal dimension or optical density of metabolic label from their matched counterparts in the opposite hemisphere (Figs. 7, 8; Table 1). The barrels farther from the transplant, in cortical territory with AChE staining density less than $40 \%$ of the unlesioned side, are significantly different as reflected in the area
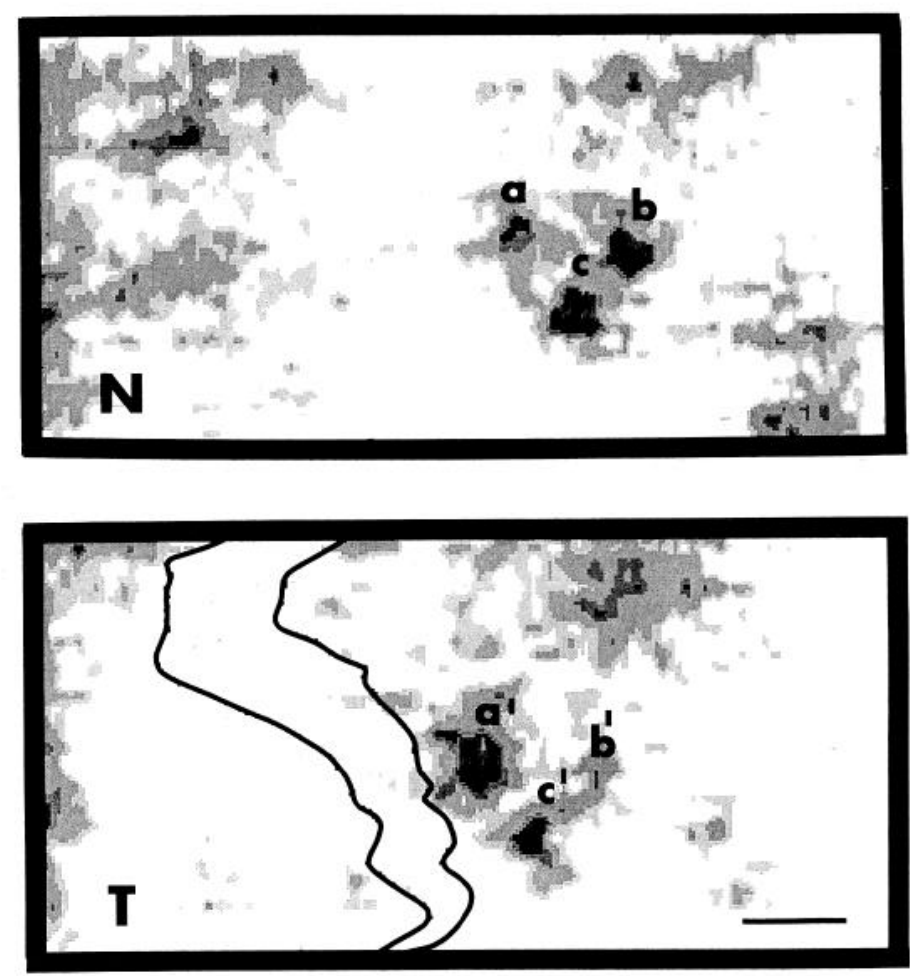

Figure 8. Two-dimensional maps of stimulus-evoked 2-DG uptake prepared as described in Materials and Methods and in Figure 7. During the 2-DG experiment, three whiskers were stimulated (B1, B3, and D1), which elicited three barrel-associated spots of activity in each hemisphere, indicated as $a, b$, and $c$ in the normal $(N)$ hemisphere and $a^{\prime}$, $b^{\prime}$, and $c^{\prime}$ in the hemisphere containing the transplant $(T)$. In this case, barrels $a^{\prime}$ and $c^{\prime}$ are within $1.5 \mathrm{~mm}$ from the transplant and display metabolic activity similar in dimension and intensity to the normal side; barrel $b^{\prime}$ is $1.9 \mathrm{~mm}$ from the transplant and reduced in dimension and intensity from $b$ in the normal hemisphere. See Figure 7 for other conventions. Medial is to the left; rostral is up. Scale bar, $1 \mathrm{~mm}$.

and optical density of the 2-DG uptake compared with their counterparts in the opposite hemisphere (Fig. 8, Table 1). In Figure 7, both barrel-associated spots of activity in the experimental hemisphere $(\mathrm{T})$ are within AChE-reinnervated cortical territory; comparison with the normal side indicates that the two sets of matched 2-DG label are of comparable size. In Figure 8 , barrels $\mathrm{a}^{\prime}$ and $\mathrm{c}^{\prime}$ of the transplanted hemisphere are also in AChE-positive cortical territory. The pattern of label in $a^{\prime}$ is larger than its companion, while the label in $\mathrm{c}^{\prime}$ is comparable in size to its matched counterpart. The label associated with barrel $b^{\prime}$, which lies outside AChE-reinnervated cortical territory, is substantially decreased in size compared to the uptake in its companion barrel in the contralateral normal hemisphere.

Figure 9 is a 2-DG autoradiograph taken from the animal whose cortical map is represented in Figure 8 . The transplant lies adjacent to the PMBSF; the levels of 2-DG uptake in the transplant are slightly decreased in intensity compared to the surrounding cortex. Two barrel-like spots of activity can be seen in each hemisphere. The barrel close to the transplant lies within $1.5 \mathrm{~mm}$ from the edge of the transplant (solid arrow) and the label evoked in it is of comparable size to its companion spot in the contralateral hemisphere. The barrel situated more lateral is $1.9 \mathrm{~mm}$ from the transplant (open arrow) and the activity evoked in it is reduced in dimension relative to its counterpart in the opposite hemisphere. 


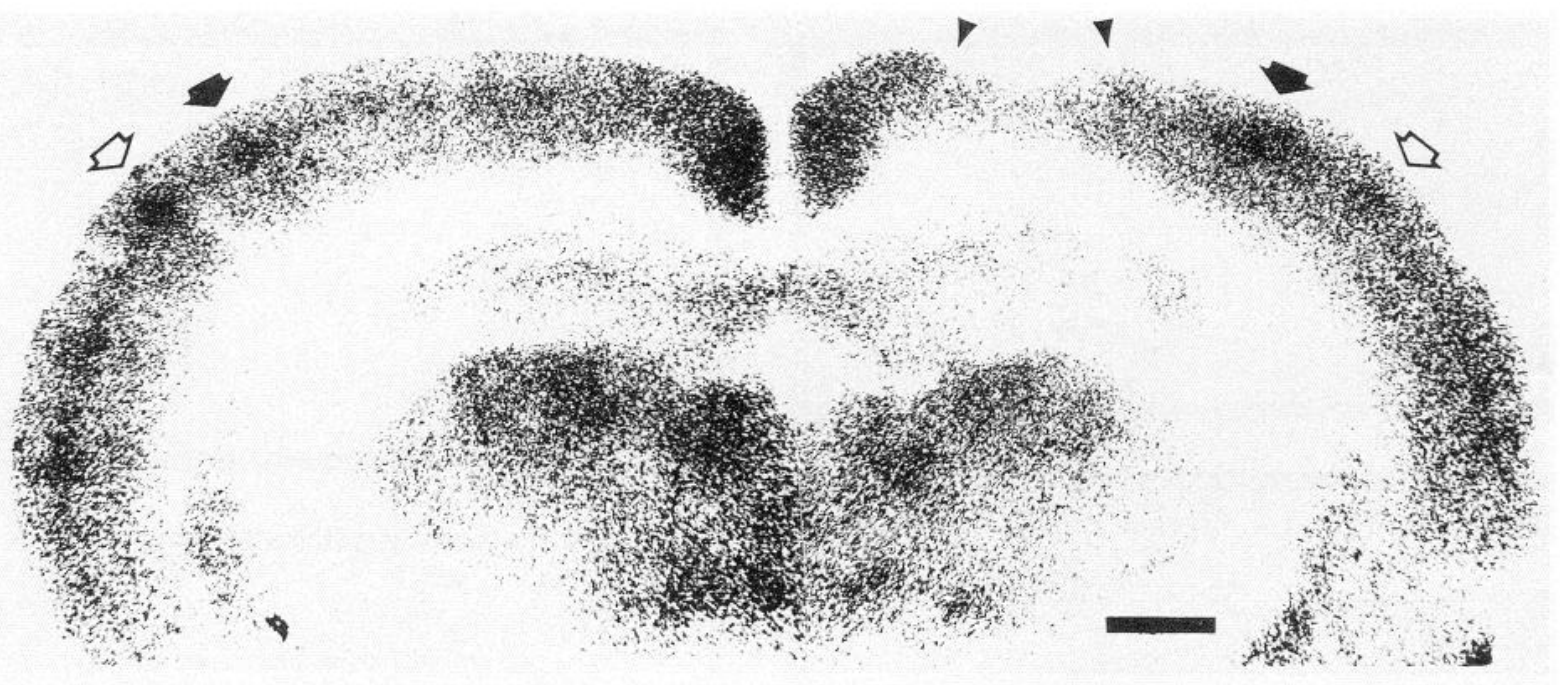

Figure 9. An autoradiograph taken from an animal that received an embryonic basal forebrain transplant indicated by the arrowheads. The autoradiograph was photographed directly from the film and is not digitized. Two regions of barrel-associated increased uptake can be seen in both hemispheres; each pair of arrows (open and solid) indicate matching barrels. The solid arrows point to activity evoked in the normal hemisphere (on the left) and activity evoked in a barrel relatively near to the transplant (on the right). The barrel-associated 2-DG label of these activated barrels is similar in dimension. The open arrows point to a barrel in the normal hemisphere and a barrel $1.9 \mathrm{~mm}$ from the transplant. The spot of activity farther from the graft is decreased in dimension from its companion on the opposite side. Scale bar, $1 \mathrm{~mm}$.

A paired $t$ test indicates that the areas of the spots of 2-DG uptake in barrels within $1.5 \mathrm{~mm}$ from the transplant are similar to those in the opposite hemisphere (Fig. 10), while the areas of the labeled spots outside the AChE-positive territory are significantly different from their matched counterparts in the opposite hemisphere (Fig. 11).

We also assessed the difference in size between the matched pairs of activated barrels as a group. In order to do this, the

Table 1. Optical density levels of 2-DG activity associated with activated barrels in normal and transplanted hemispheres

\begin{tabular}{|c|c|c|c|c|c|}
\hline \multicolumn{2}{|c|}{$\mathrm{BF}$ and $\mathrm{AChE}^{+}$} & \multicolumn{2}{|c|}{$\underline{\mathrm{BF}}$ and $\mathrm{AChE}^{-}$} & \multicolumn{2}{|c|}{ Cortex and $\mathrm{AChE}$} \\
\hline $\begin{array}{l}\mathrm{N} \\
(\bar{X}= \\
76.52)\end{array}$ & $\begin{array}{l}\mathrm{T} \\
(\bar{X}= \\
76.13)\end{array}$ & $\begin{array}{l}\mathrm{N} \\
(\bar{X}= \\
65.76)\end{array}$ & $\begin{array}{l}\mathrm{T}^{a} \\
(\bar{X}= \\
63.39)\end{array}$ & $\begin{array}{l}\mathrm{N} \\
(\bar{X}= \\
66.19)\end{array}$ & $\begin{array}{l}\mathrm{T} \\
(\bar{X}= \\
64.05)\end{array}$ \\
\hline 71.86 & 74.05 & 71.15 & 69.24 & 56.12 & 60.69 \\
\hline 78.82 & 76.00 & 66.19 & 67.49 & 58.88 & 59.20 \\
\hline 82.92 & 82.02 & 63.25 & 60.25 & 62.91 & 58.09 \\
\hline 74.06 & 76.26 & 75.98 & 72.66 & 63.74 & 61.93 \\
\hline 80.70 & 82.57 & 66.02 & 66.42 & 65.74 & 59.47 \\
\hline 76.65 & 74.88 & 62.35 & 59.68 & 73.52 & 68.09 \\
\hline \multirow[t]{2}{*}{70.61} & 67.15 & 66.33 & 58.95 & 75.45 & 72.74 \\
\hline & & 54.77 & 52.46 & 73.16 & 72.22 \\
\hline
\end{tabular}

The optical density value for a given activated barrel in a transplanted hemisphere was matched with its equivalent in the opposite hemisphere. Mean optical density values of stimulus-evoked 2-DG uptake are expressed as a percentage above background; background is white matter. Optical density values were obtained from the autoradiographs.

$\mathrm{BF}$ and $\mathrm{AChE}^{+}$refers to cortical territory in basal forebrain-transplanted hemispheres where AChE-positive staining is at least $85 \%$ of the contralateral normal hemisphere. $B F$ and $A C h E^{-}$refers to basal forebrain-transplanted hemisphere regions with $30-40 \%$ AChE-positive staining compared to normal. Cortex and $A C h E^{-}$refers to neocortical-transplanted hemispheres (control) where AChEpositive staining is $25-40 \%$ of normal. $N$, normal hemisphere; $T$, lesioned and transplanted hemisphere.

"Activated barrels in basal forebrain-transplanted hemispheres that lay outside the region of cortical $\mathrm{AChE}$ reinnervation (BF and $\mathrm{AChE}^{-}$) demonstrate signifcantly reduced levels of 2-DG activity compared to their paired counterparts in the contralateral hemisphere (paired $t$ test, $p<0.05$ ). percentage difference between the areas of activated barrels was determined. For each group of matching pairs [group A, spots of label associated with barrels close to basal forebrain transplants and their matching normal counterparts (i.e., BF \& $\mathrm{AChE}^{+}$); group $\mathrm{B}$, spots of label associated with barrels far from basal forebrain transplants and their counterparts (i.e., BF \& $\mathrm{AChE}^{-}$); and group $\mathrm{C}$, spots of label associated with barrels in hemispheres with neocortical control grafts and their normal

\section{Area of 2DG uptake associated with barrels in $\mathrm{AChE}+$ cortex}

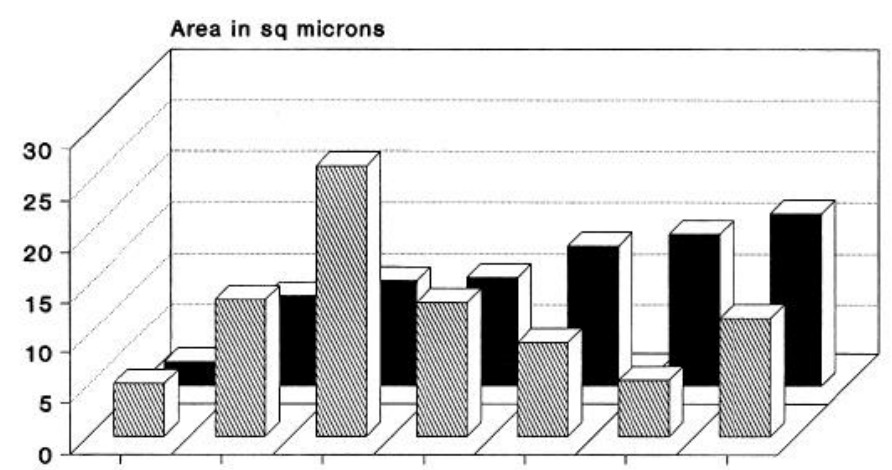

MMWW BF \& AChE+ Normal

Animals receiving BF transplant

Figure 10. Bar graph illustrating the area (in $\mu \mathrm{m}^{2}$ ) of barrel-associated spots of 2-DG uptake, in response to whisker stimulation, taken from both hemispheres of animals that received a basal forebrain transplant. The hatched bars indicate measurements of 2-DG uptake associated with activated barrels in regions of transplanted hemispheres where cortical AChE innervation is at least $85 \%$ of normal $\left(B F \& A C h E^{+}\right)$. The solid bars indicate areal measurements of label evoked in the corresponding barrels in the normal hemisphere. The areas of the spots of label were measured on the two-dimensional maps according to procedures described in the text. The two populations of areal measurements were not significantly different (paired $t$ test). $B F$, basal forebrain. 


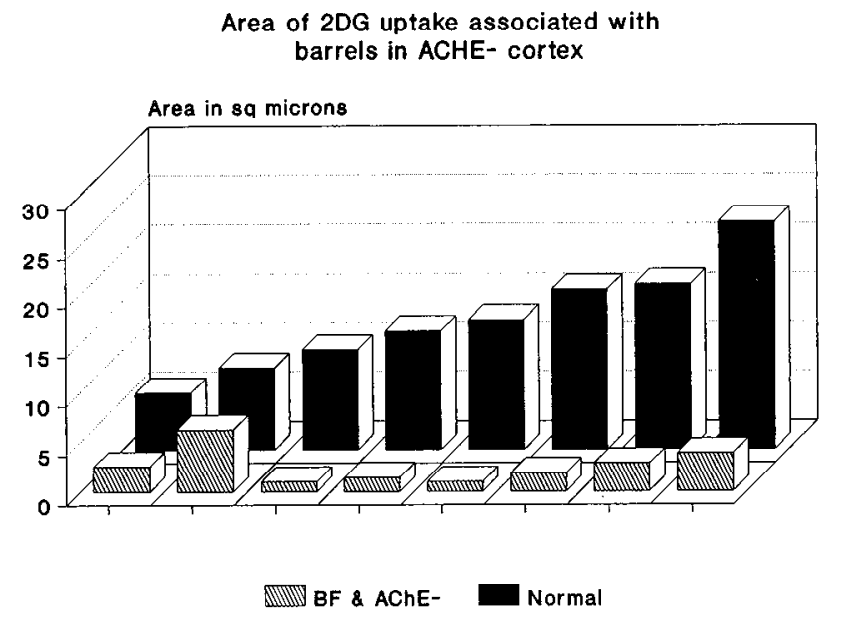

Animals receiving $B F$ transplant

Figure 11. Bar graph illustrating the areal measurements of barrelassociated spots of label in both hemispheres of animals receiving basal forebrain transplants. The measurements taken in the transplanted hemisphere were in cortical territory that was AChE depleted (i.e., $40 \%$ of normal, $B F \& A C h E^{-}$), indicated with hatched bars; the measurements in the opposite hemisphere are indicated with solid bars. See Figure 10 and Results for details. Significant differences were found between the areas of activated barrels in the AChE-depleted cortical territory in basal forebrain-transplanted hemispheres compared to cquivalent barrcls in the normal hemispheres (paired $t$ test, $p<0.01$ ). $B F$, basal forebrain.

counterparts (i.e., Cortex \& $\mathrm{AChE}^{-}$)], the area of the activated barrel in the normal hemisphere was considered to be $100 \%$. The size of the activated barrel in the experimental hemisphere was expressed as a percentage of its normal counterpart. A statistically significant difference was found when the percentage size difference of the group A patches of 2-DG uptake (BF \& $\mathrm{AchE}^{+}$) was compared to the percentage size difference of the patches in either group B (BF \& $\left.\mathrm{AChE}^{-}\right)$[ANOVA, $F(1,20)=$ $8.10, p<0.001]$ or group $\mathrm{C}$ (Cortcx \& $\left.\mathrm{AChE}^{-}\right)$(Fig. 12). No differences were found when group $C$ was compared with group $B$. We also evaluated the overall relationship between amount of AChE innervation and size of 2-DG uptake in a barrel and found a statistically significant correlation $(p<0.05)$ as seen in Figure 13.

Animals receiving neocortical control transplants. Figure 14 is an example of a cortical map generated from an animal that received a basal forebrain lesion and a control transplant of neocortical tissue. Three vibrissae were bilaterally and symmetrically stimulated during the $2-\mathrm{DG}$ experiment. The three activated regions in the experimental hemisphere lie within 1.5 $\mathrm{mm}$ from the transplant. When the areal dimensions of the 2-DG activity associated with the barrels in the experimental hemisphere were compared to their counterparts in the opposite hemisphere, they were found to be significantly reduced in size (Fig. 14). Although the spots of activity are within close proximity to the transplant, the AChE staining density in these sites is $35 \%$ of staining density in the opposite nonlesioned hemisphere. The decrease in the area of the activity associated with the barrels in control-transplanted hemispheres is a consistent finding, as demonstrated in Figures 13 and 15.

The percentage difference between the areas of matched pairs of activated barrels in control-grafted animals (group $\mathrm{C}$ as defined above) was significantly different from the percentage area

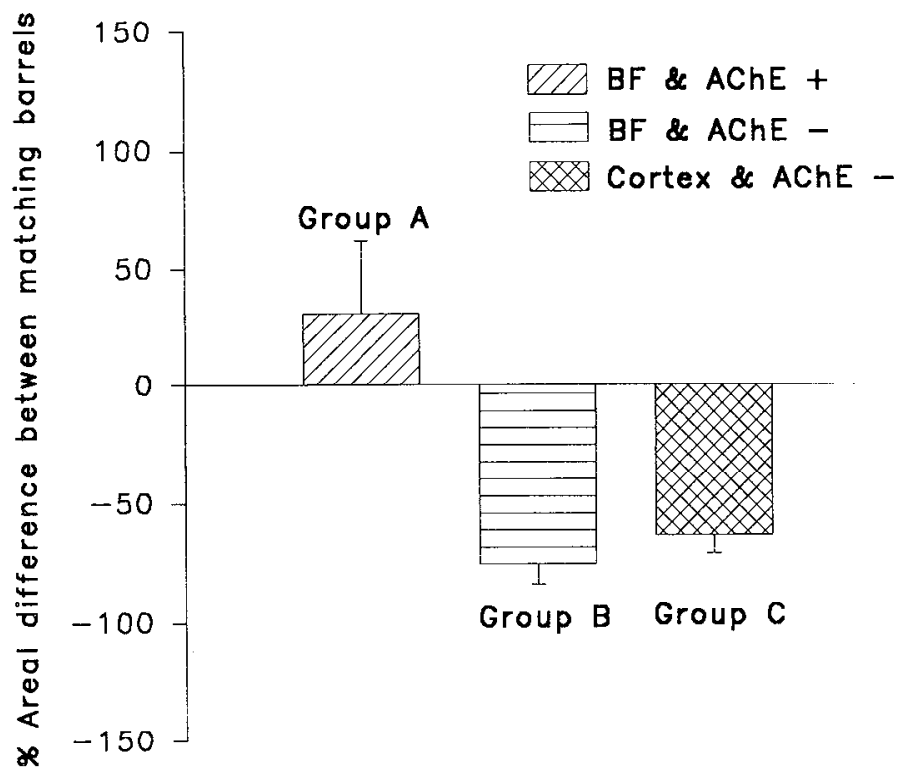

Figure 12. Bar graph illustrating the percentage difference in areal measurements of activated barrels in transplanted hemispheres expressed as a percentage of corresponding matched barrels in normal hemispheres. Group $A\left(B F \& A C h E^{\prime}\right)$, activated barrels in basal forebrain-transplanted hemispheres within cortical territory containing at least $85 \%$ of $\mathrm{AChE}$ staining levels of the contralateral unlesioned hemispheres; Group $B\left(B F \& A C h E^{-}\right)$, activated barrels in basal forebraintransplanted hemispheres within cortical territory containing $30-40 \%$ of AChE staining levels of the contralateral hemispheres; Group $C$ (Cortex \& $A\left(h E^{-}\right.$), activated barrels in neocortical control-transplanted hemispheres within cortical territory containing $25-40 \%$ of AChE staining levels of the contralateral hemispheres. Group $A$ is significantly different from Group $B(p<0.001)$. Group $A$ is significantly different from Group $C(p<0.01)$. Groups $B$ and $C$ are not significantly different.

difference of barrels in AChE-reinnervated territory of basal forebrain-transplanted animals (group A) [ANOVA, $F(1,20)=$ $14.00, p=0.01]$, but not those outside the region of AChE reinnervation (group B) (Fig. 12). Optical density measurements were obtained demonstrating that the intensity of metabolic activity in the activated barrels in control-transplanted hemispheres was not significantly different compared to the corresponding values in contralateral hemispheres (Table 1).

\section{Discussion}

The results of these experiments suggest that cell-suspension transplants of embryonic cholinergic basal forebrain tissue (1) increase the density of AChE staining surrounding the transplant and (2) if sufficiently close to activated barrels, can ameliorate deficits in stimulus-evoked metabolic activity resulting from basal forebrain lesions. Control transplants of neocortical tissue did not result in such improvements.

\section{The effect of basal forebrain lesions on cortical function}

It is widely accepted that basal forebrain lesions can profoundly impair cortical cholinergic functions, with less clear-cut impact on other neurotransmitter systems (for review, see Dekker et al., 1991). The evidence supporting this stems from a number of sources, including previous investigations by this laboratory of the effect of basal forebrain lesions on metabolic activity. 'The metabolic studies determined that 2-DG uptake in response to stimulation was decreased in the somatosensory cortex ipsilateral to the lesion (Ma et al., 1989; Juliano et al., 1990; Jacobs 
Figure 13. A scatterplot indicating the relationship between the amount of AChE in the transplanted and lesioned hemispheres (expressed on the abscissa as a percentage of the opposite, unlesioned hemisphere) and the size of the 2-DG spots of label evoked in the same regions. The area of the barrel-associated spots of label is expressed on the ordinate as the percentage difference between matched loci in each hemisphere. Each symbol refers to a given spot of 2-DG uptake. See text for details regarding computation of percentage difference. $\square B F \& A C h E^{+}$refers to spots of label close to a basal forebrain transplant and in cortical territory with $\mathrm{AChE}$ innervation at least $85 \%$ of the normal hemisphere; $\diamond B F \& A C h E$ - refers to spots of label far from a basal forebrain transplant and in cortical territory with AChE innervation less than $85 \%$ of the normal hemisphere; ${ }^{*}$ Cortex and $A C h E^{-}$refers to labeled foci in hemispheres receiving a neocortical transplant and with AChE innervation less than $85 \%$ of the normal hemisphere.

\section{Relationship between AChE innervation \& area of barrel-associated 2DG uptake}

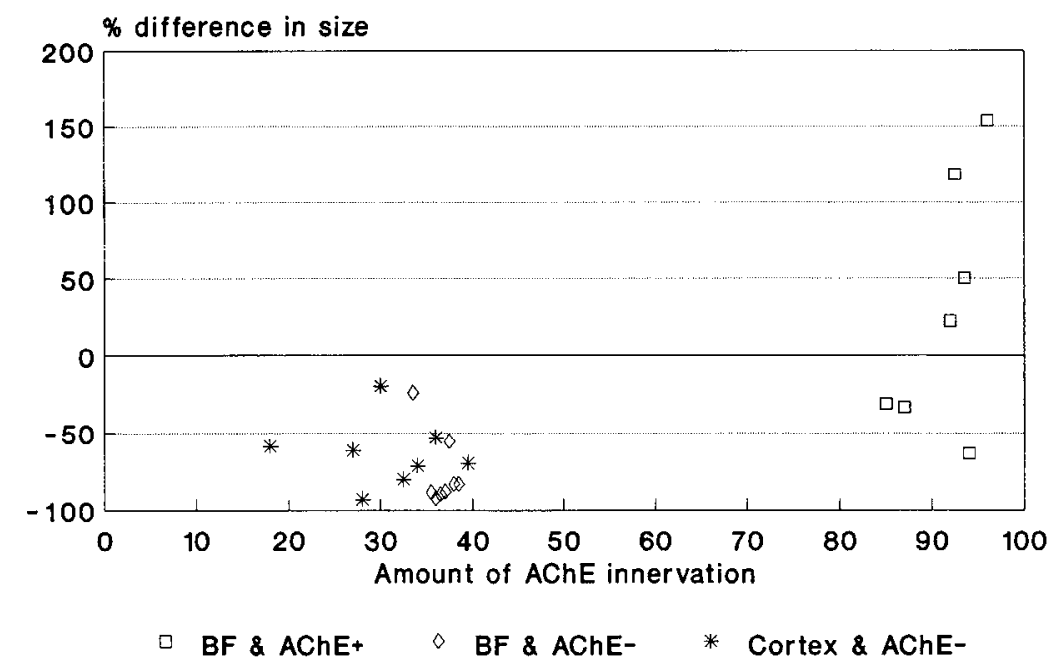

et al., 1991). Although basal forebrain lesions almost certainly destroy several classes of neurons, we interpreted the reductions in stimulus-evoked 2-DG activity as most likely due to depletion of cortical ACh. Our interpretation was supported in part by the finding that similar reductions in stimulus-evoked activity resulted after topical application of a muscarinic antagonist to the somatosensory cortex (Juliano et al., 1990). In addition, cortical $\mathrm{CO}$ staining and baseline cortical 2-DG uptake ipsilateral to the lesion were normal, suggesting that thalamocortical afferent fibers were not disrupted (Ma et al., 1989; Juliano et al., 1990).

Basal forebrain lesions do not appear to cause substantial reductions in cortical levels of other neurotransmitters, such as somatostatin, noradrenaline, dopamine, GABA, or 5-HT (Johnston et al., 1981; McKinney et al., 1982; Dubois et al., 1985; Fine et al., 1987; Höhmann et al., 1987). Conversely, behavioral impairments induced by basal forebrain lesions are improved by treatments with drugs that enhance or mimic the action of $\mathrm{ACh}$ (see Dekker et al., 1991, for review), suggesting that $\mathrm{ACh}$ is the functionally relevant substance depleted by the lesions. In addition, a number of studies emphasize the specific effects of cholinergic depletion on certain cortical processes. For example, research evaluating the role of $\mathrm{ACh}$ on the development of cortical morphology in mice determined that only basal forebrain lesions, and not those known to deplete cortical norepinephrine or 5-HT, resulted in abnormal cortical cytoarchitecture (Höhmann et al., 1988). In a different study evaluating changes in 2-DG uptake, Levin et al. (1988) determined that noradrenergic-depleting lesions of the locus coeruleus in rats resulted in expansion of stimulus-evoked 2-DG uptake in individual barrels, in contrast to the reductions caused by cortical ACh depletion. Furthermore, ACh-rich transplants inserted into neocortex or hippocampus depleted of ACh lead to substantial improvements in memory and attention, while grafts of tissue containing other neurotransmitters do not result in behavioral improvement (Fine et al., 1985b; Collier, 1990; Dunnett, 1990, 1991; Kimble, 1990; Ridley et al., 1992).

\section{Basal forebrain transplants restore activity toward normal}

For the reasons described above, we consider it likely that increases in 2-DG uptake seen after transplantation of embryonic basal forebrain are due to graft-derived cholinergic reinnervation of adjacent neocortex. While it is likely that cholinergic neurons are only a minority among the constituents of these grafts, many of the other neurotransmitters that might be present (e.g., GABA, glutamate, somatostatin) are common to both the basal forebrain and neocortical embryonic tissue used in this study. In addition, we found a clear correlation between the amount of AChE innervation and the increase of 2-DG uptake in the barrel region. Activated barrels adjacent to the cholinergic transplants, and within AChE-positive regions, exhibited label of comparable dimension and intensity to corresponding barrels in the contralateral normal hemisphere. This was not the case for barrels lying more than $2 \mathrm{~mm}$ from the basal forebrain transplant and outside the AChE-positive areas. The activity evoked in these "outside" areas was typical of that observed in the ACh-depleted hemispheres of our earlier studies. This may reflect a "limit" to the distance that axons can extend from these transplants. Previous investigations of cmbryonic rat cholinergic transplants into $\mathrm{ACh}$-depleted rat neocortex suggest that fiber outgrowth surrounding the graft is restricted to $1-3 \mathrm{~mm}$ (Fine et al., 1985a,b; Dunnett et al., 1986). AChE-positive fibers have been reported to extend up to $6 \mathrm{~mm}$ from intrahippocampal basal forebrain transplants placed in rats following fimbriafornix lesions, although the most intense staining occurs within 2 mm of the graft borders (Björklund and Stenevi, 1977; Nilsson et al., 1987; Shapiro et al., 1989). Kelly et al. (1985) found that 2-DG uptake in rat hippocampus, reduced by prior lesion of the septohippocampal pathway, is restored to near normal levels within $3 \mathrm{~mm}$ of the intrahippocampal cholinergic basal forebrain transplants, and the density of the AChE staining is also greatest within that region. The mechanism that permits and/ or restricts the distance that fibers extend from a transplant is not clear. Dunnett et al. (1986) proposed that since neurogenesis 

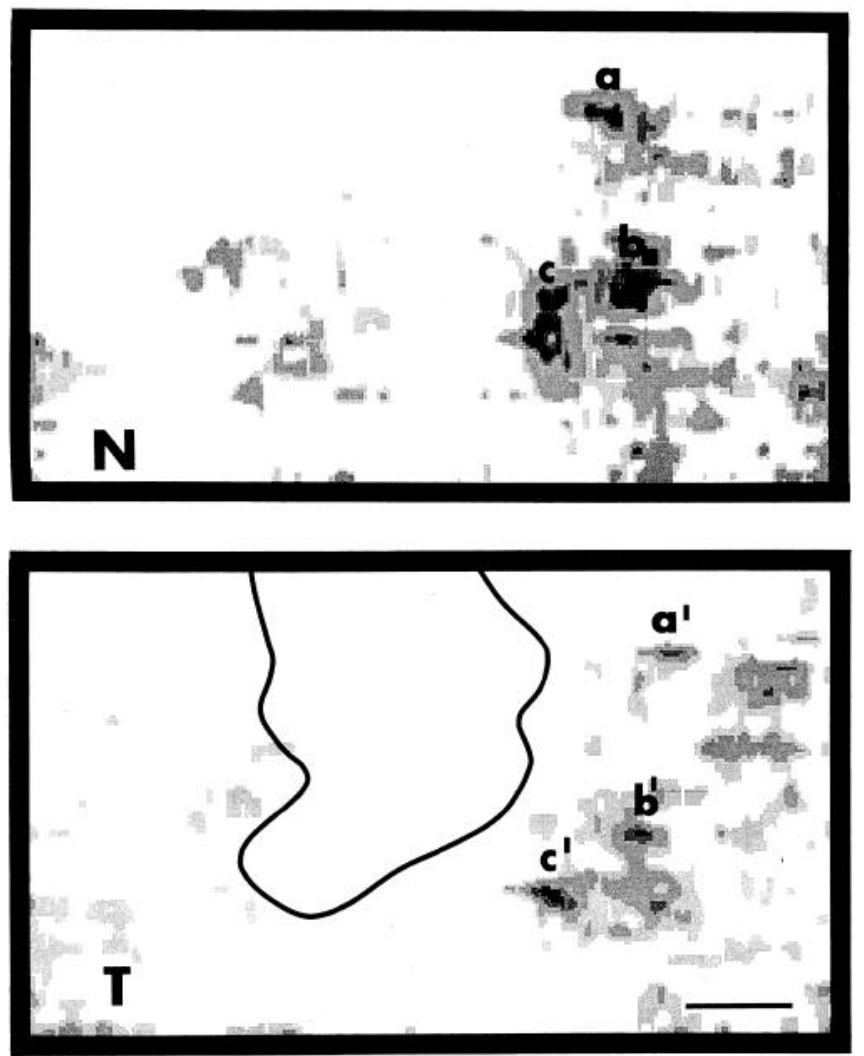

Figure 14. Two-dimensional maps of stimulus-evoked metabolic activity from an animal that received a basal forebrain lesion and a transplant of embryonic cortical tissue. During the 2-DG experiment, three whiskers were stimulated (B1, B3, D3). In the normal $(N)$ and transplanted $(T)$ hemispheres, three spots of barrel-associated label can be seen $\left(a / a^{\prime}, b / b^{\prime}, c / c^{\prime}\right)$. In the map of the hemisphere with the transplant $(T)$, all the barrel-associated spots of activity are reduced in dimension compared with their companions in the normal side $(N)$. All these diminished spots of label were also within $2 \mathrm{~mm}$ from the transplant and in cortical territory with less than $35 \%$ of AChE-positive fibers in the opposite hemisphere. See Materials and Methods and Figures 7 and 8 for conventions and details. Medial is to the left; rostral is up. Scale bar, $1 \mathrm{~mm}$.

continues into adult life in the hippocampus (Angevine, 1965; Bayer, 1980; Stanfield and Cowen, 1988), a prolonged accessibility to trophic factors may account for the greater distance of AChE-positive fiber outgrowth. It is also possible that the inherent maturity of the transplant may determine the extent of axonal outgrowth; after an implant reaches a mature age, axons may stop growing.

The improvements in stimulus-evoked 2-DG uptake following cholinergic transplantation and subsequent reinnervation, as demonstrated by AChE staining, can be understood in light of the significant role that ACh plays in the processing of information in sensory regions of neocortex. Many studies have shown that $\mathrm{ACh}$ enhances neural activity through a mechanism depressing potassium permeability (Krnjević et al., 1971; Halliwell and Adams, 1982; Brown, 1983; McCormick and Prince, 1985). In neocortex, this effect is particularly evident in response to specific stimulation. In other words, $\mathrm{ACh}$ is more effective when coupled with an appropriate stimulus (Metherate et al., 1987, 1988b; Sillito and Murphy, 1987; Dykes, 1990). In addition, ACh appears to facilitate long-term enhancement of cortical responses and contribute to neural plasticity in both adult
Area of 2DG uptake associated with barrels in AChE- cortex

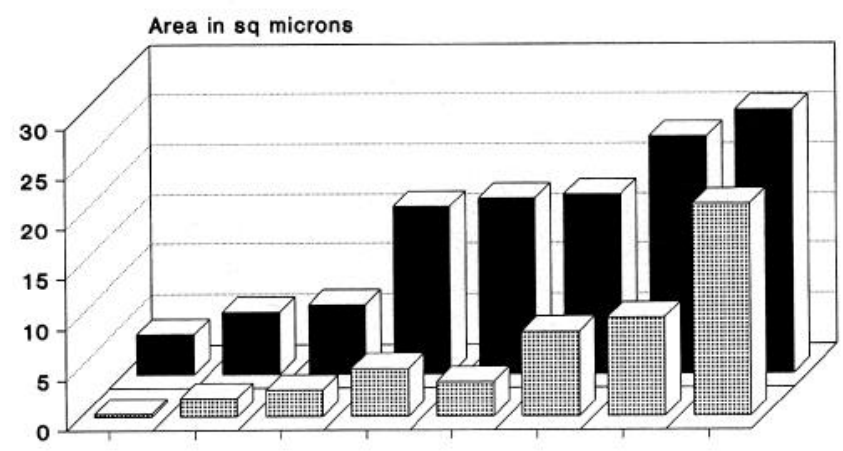

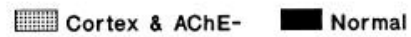

Animals receiving neocortical transplant

Figure 15. Bar graph illustrating areas of barrel-associated 2-DG uptake in animals that received neocortical transplants following basal forebrain lesions. The transplanted hemispheres contained $25-40 \%$ of AChE staining in the opposite hemisphere. Measurements of stimulusevoked spots of label in the AChE-depleted hemispheres containing the transplant (Cortex \& $A C h E^{-}$, dotted bars) and their matched counterparts in the normal hemispheres (solid bars) were significantly different (paired $t$ test, $p<0.01$ ).

and neonatal animals (Bear and Singer, 1986; Rasmusson and Dykes, 1988; Dykes, 1990; Juliano et al., 1991; Webster et al., 1991). As suggested in our earlier studies, the absence of ACh may lead to a diminished cortical response to somatic stimulation, reflected in a smaller than normal spot of 2-DG label (Ma et al., 1989; Jacobs et al., 1990). Restoring ACh to the somatosensory cortex may facilitate a more expansive response. It is not surprising, therefore, that replacement of $\mathrm{ACh}$ in deprived cortex by transplants of ACh-rich tissue increases the strength of neural responses to stimulation, reflected as increased 2-DG uptake. A recent finding by Nilsson and Björklund (1992) reinforces the notion that heightened metabolic uptake seen here reflects a cholinergic enhancement of activity in response to a functional demand. These authors report that ACh-rich transplants into animals with fimbria-fornix lesions differentially release $\mathrm{ACh}$ as required by the host under distinct behavioral conditions.

Our present results also reveal a slight improvement in the optical density of barrel-associated 2-DG activity near (i.e., within $2 \mathrm{~mm}$ ) the "control" neocortical transplants, but also in ACh-depleted territory. Although these patches of label were significantly reduced in size from their normal counterparts, they were not as small as the barrel-associated spots of uptake located greater than $2 \mathrm{~mm}$ from the basal forebrain transplants. That is, there seemed to be a small, but not significant, benefit derived from proximity to a transplant, neocortical or basal forebrain. The reason for the slight increase in density and size of the control-grafted animals is not clear. It is unlikely that ACh played a role, since no evidence for cholinergic innervation was seen in the AChE staining pattern associated with the neocortical tissue transplants. The surrounding cortex had less than $40 \%$ of the AChE staining density of the opposite unlesioned hemisphere. It is possible, as has been suggested by others, that unidentified trophic factors participate in functional improve- 
ments noted after grafting (e.g., Björklund et al., 1987). If present in this case, these trophic factors may be able to elicit only limited improvements, since despite the slight increases in barrel-associated optical density values near the control transplants, the area of cortex activated by whisker stimulation was still significantly smaller than normal. This suggests that such trophic effects, if present, are not sufficient to restore the normal levels of neural activation in response to stimulation of a given whisker, as cholinergic grafts are able to do.

We also observed variability in the size of whisker-evoked label within the cortical territory that received adequate AChE innervation, although the differences between hemispheres were not significant (see Fig. 10). It is not clear what accounts for the lack of consistency in 2-DG uptake among this group (BF \& $\mathrm{AChE}^{+}$). The size differences may be related to the relative completeness of AChE innervation or to unspecified trophic factors, as suggested above. This variability is most likely not due to differences in side-to-side stimulation during the 2-DG injections, since prior studies involving normal and sham-lesioned animals did not find hemispheric differences in 2-DG uptake within barrel cortex after similar manual stimulation (Ma et al., 1989; Jacobs et al., 1990; Jacobs and Juliano, 1992).

\section{Clinical implications}

Reduction of cortical ACh is associated with many dementias including Alzheimer's disease, Korsakoff's syndrome, and Parkinson's disease with dementia. It is still not clear that augmentation of neurotransmitters through transplantation is an appropriate therapy for humans with disease processes that may require treatment substantially more complex than replacement of a single substance. Recent results from transplantation of dopaminergic cells into animal models of Parkinson's disease, and into some humans, have provided optimism for the possibility of improvements in motor impairments associated with this disease (Lindvall et al., 1990; for review, see Lindvall, 1991; Freed et al., 1992). In addition, numerous studies in ACh-depleted animals, demonstrating cognitive improvements following basal forebrain transplants (Ridley et al., 1991, 1992), sustain the possibility of human treatment with transplantation in the future. Observations that deficits in somatosensory processing are present in patients with Alzheimer's disease (Freedman and Oscar-Berman, 1987) underscore the significance of the results reported here.

\section{References}

Angevine JB (1965) Time of neuron origin in the hippocampal region: an autoradiographic study in the mouse. Exp Neurol 13[Suppl 2]:170.

Arendt T, Allen Y, Marchbanks RM, Schugens MM, Sinden J, Lantos PL, Gray JA (1989) Cholinergic system and memory: effects of chronic ethanol, embryonic basal forebrain transplants and excitotoxic lesions of cholinergic basal forebrain projection system. Neuroscience 33:435-462.

Bayer SA (1980) Development of the hippocampal region in the rat. I. Neurogenesis examined with ${ }^{3} \mathrm{H}$-thymidine autoradiography. J Comp Neurol 190:87-114.

Bear MF, Singer W (1986) Modulation of visual cortical plasticity by acetylcholine and noradrenaline. Nature 320:172-176.

Björklund A, Stenevi U (1977) Reformation of the severed septohippocampal cholinergic pathway in the adult rat by transplanted septal neurons. Cell Tissue Res 185:289-302.

Björklund A, Stenevi U, Schmidt RH, Dunnett SB, Gage FH (1983) Intracerebral grafting of neuronal cell suspensions. I. Introduction and general methods of preparation. Acta Physiol Scand 522[Suppl]: $1-7$

Björklund A, Lindvall O, Isacson O, Brundin P, Wictorin K, Strecker
RE, Clarke DJ, Dunnett SB (1987) Mechanisms of action of intracerebral neural implants: studies on nigral and striatal grafts to the lesioned striatum. Trends Neurosci 10:509-516.

Brown DA (1983) Slow cholinergic excitation-a mechanism for increasing neuronal excitability. Trends Neurosci 6:302-307.

Buzsáki G, Gage FH, Kellényi L, Björklund A (1987) Behavioral dependence of the electrical activity of intracerebrally transplanted fetal hippocampus. Brain Res 400:321-333.

Collier TJ (1990) Neural transplantation in Alzheimer's disease: the evidence from animal models. In: Alzheimer's and Parkinson's diseases (Altman HJ, Altman BN, eds), pp 291-324. New York: Plenum.

Dekker AJAM, Connor DJ, Thal LJ (1991) The role of cholinergic projections from the nucleus basalis in memory. Neurosci Biobehav Rev 15:299-317.

Donoghue JP, Carroll KL (1987) Cholinergic modulation of sensory responses in rat primary somatic sensory cortex. Brain Res 408:367371 .

Dubois B, Mayo W, Agid Y, Le Moal M, Simon H (1985) Profound disturbances of spontaneous and learned behaviors following lesions of the nucleus basalis magnocellularis in the rat. Brain Res 338:249258.

Dunnett SB (1990) Neural transplantation in animal models of dementia. Eur J Neurosci 2:567-587.

Dunnett S (1991) Cholinergic grafts, memory and ageing. Trends Neurosci 14:371-376.

Dunnett SB, Toniolo G, Fine A, Ryan CN, Björklund A, Iversen SD (1985) Transplantation of embryonic ventral forebrain neurons to the neocortex of rats with lesions of nucleus basalis magnocellularisII. Sensorimotor and learning impairments. Neuroscience 16:787797.

Dunnett SB, Whishaw IQ, Bunch ST, Fine A (1986) Acetylcholinerich ncuronal grafts in the forcbrain of rats: cffcets of environmental enrichment, neonatal noradrenaline depletion, host transplantation site and regional source of embryonic donor cells on graft size and acetylcholinesterase-positive fibre outgrowth. Brain Res 378:357-373.

Dykes RW (1990) Acetylcholine and neuronal plasticity in somatosensory cortex. In: Brain cholinergic systems (Steriade M, Biesold D, eds), pp 294-313. New York: Oxford UP.

Fine A, Dunnett SB, Björklund A, Clarke D, Iversen SD (1985a) Transplantation of embryonic ventral forebrain neurons to the neocortex of rats with lesions of nucleus basalis magnocellularis-I. Biochemical and anatomical observations. Neuroscience 16:769-786.

Fine A, Dunnett SB, Björklund A, Iversen SD (1985b) Cholinergic ventral forebrain grafts into the neocortex improve passive avoidance memory in a rat model of Alzheimer disease. Proc Natl Acad Sci US $\Lambda$ 82:5227-5230.

Fine A, Pittaway K, de Quidt M, Czudek C, Reynolds GP (1987) Maintenance of cortical somatostatin and monoamine levels in the rat does not require intact cholinergic innervation. Brain Res 406: 326-329.

Freed CR, Breeze RE, Rosenberg NL, Schneck SA, Kriek E, Qi J-X, Lone T, Zhang Y-B, Snyder JA, Wells TH, Ramig LO, Thompson L, Mazziotta JC, Huang SC, Grafton ST, Brooks D, Sawle G, Schroter $G$, Ansari AA (1992) Survival of implanted fetal dopamine cells and neurologic improvement 12 to 46 months after transplantation for Parkinson's Disease. N Engl J Med 327:1549-1555.

Freedman M, Oscar-Berman M (1987) Tactile discrimination learning deficits in Alzheimer's and Parkinson's diseases. Arch Neurol 44:394398.

Halliwell JV, Adams PR (1982) Voltage-clamp analysis of muscarinic excitation in hippocampal neurons. Brain Res 250:71-92.

Hodges H, Allen Y, Sinden J, Lantos PL, Gray JA (1990) Cholinergicrich transplants alleviate cognitive deficits in lesioned rats, but exacerbate response to cholinergic drugs. In: Progress in brain research, Vol 82 (Dunnett SB, Richards SJ, eds), pp 347-358. New York: Elsevier.

Höhmann CF, Wenk GL, Lowenstein P, Brown ME, Coyle JT (1987) Age-related recurrence of basal forebrain lesion-induced cholinergic deficits. Neurosci Lett 82:253-259.

Höhmann CF, Brooks AR, Coyle JT (1988) Neonatal lesions of the basal forebrain cholinergic neurons result in abnormal cortical development. Dev Brain Res 42:253-264.

Jacobowitz DM, Creed GJ (1983) Cholinergic projection sites of the nucleus of tractus diagonalis. Brain Res Bull 10:365 371.

Jacobs SE, Juliano SL (1992) The effect of cortical acetylcholine depletion on sensory processing in rats. Soc Neurosci Abstr 18:1543. 
Jacobs SE, Fine A, Juliano SL (1990) Transplants of embryonic ventral forebrain into cholinergically depleted rats restore diminished metabolic uptake in barrel cortex. Soc Neurosci Abstr 16:469.

Jacubs SE, Code RA, Juliano SL (1991) Basal forebrain lesions alter stimulus-evoked metabolic activity in rat somatosensory cortex. Brain Res 560:342-345.

Johnston MV, McKinney M, Coyle JT (1979) Evidence for a cholinergic projection to neocortex from neurons in basal forebrain. Proc Natl Acad Sci USA 76:5392-5396.

Johnston MV, McKinney M, Coyle JT (1981) Neocortical cholinergic innervation: a description of extrinsic and intrinsic components in the rat. Exp Brain Res 43:159-172.

Juliano SL, Ma W, Bear MF, Eslin D (1990) Cholinergic manipulation alters stimulus-evoked metabolic activity in cat somatosensory cortex. J Comp Neurol 297:106-120.

Juliano SL, Ma W, Eslin D (1991) Cholinergic depletion prevents expansion of topographic maps in somatosensory cortex. Proc Natl Acad Sci USA 88:780-784.

Kelly PAT, Gage FH, Ingvar M, Lindvall O, Stenevi U, Björklund A (1985) Functional reactivation of the deafferented hippocampus by embryonic septal grafts as assessed by measurements of local glucose utilization. Exp Brain Res 58:570-579.

Kimble DP (1990) Functional effects of neural grafting in the mammalian central nervous system. Psychol Bull 108:462-479.

Koelle GB (1955) The histochemical identification of acetylcholinesterase in cholinergic, adrenergic and sensory neurons. J Pharmacol Exp Ther 114:167-184.

Krnjevic K, Pumain R, Renaud L (1971) The mechanism of excitation by acetylcholine in the cerebral cortex. J Physiol (Lond) 215:217268.

Lamour Y, Dutar P, Jobert A, Dykes RW (1988) An iontophoretic study of single somatosensory neurons in rat granular cortex serving the limbs: a laminar analysis of glutamate and acetylcholine effects on receptive-field properties. J Neurophysiol 60:725-750.

Levin BE, Craik RL, Hand PJ (1988) The role of norepinephrine in adult rat somatosensory (SmI) cortical metabolism and plasticity. Brain Res 443:261-271.

Lindvall O (1991) Prospects of transplantation in human neurodegenerative diseases. Trends Neurosci 14:376-384.

Lindvall O, Brundin P, Widner H, Rehncrona S, Gustavii B, Frackowiak R, Leenders KL, Sawle G, Rothwell JC, Marden CD, Björklund A (1990) Grafts of fetal dopamine neurons survive and improve motor function in Parkinson's disease. Science 247:574-577.

Low WC, Lewis PR, Bunch ST, Dunnett SB, Thomas SR, Iversen SD, Björklund A, Stenevi U (1982) Function recovery following neural transplantation of embryonic septal nuclei in adult rats with septohippocampal lesions. Nature 300:260-262.

Ma W, Höhmann CF, Coyle JT, Juliano SL (1989) Lesions of the basal forebrain alter stimulus-evoked metabolic activity in mouse somatosensory cortex. J Comp Neurol 288:414-427.

McCormick DA, Prince DA (1985) Two types of muscarinic response to acetylcholine in mammalian cortical neurons. Proc Natl Acad Sci USA 82:6344-6348.

McKenna TM, Ashe JH, Weinberger NM (1989) Cholinergic modulation of frequency receptive fields in auditory cortex: I. Frequencyspecific effects of muscarinic agonists. Synapse 4:30-43.

McKinney M, Davies P, Coyle JT (1982) Somatostatin is not colocalized in cholinergic neurons innervating the rat cerebral cortexhippocampal formation. Brain Res 243:169-172.

Mesulam M-M, Mufson EJ, Wainer BH, Levey AI (1983) Central cholinergic pathways in the rat: an overview based on an alternative nomenclature (Ch1-Ch6). Neuroscience 10:1185-1201.

Metherate R, Weinberger NM (1989) Acetylcholine produces stimulus-specific receptive field alterations in cat auditory cortex. Brain Res 480:372-377.

Metherate R, Weinberger NM (1990) Cholinergic modulation of responses to single tones produces tone-specific receptive field alterations in cat auditory cortex. Synapse 6:133-145.

Metherate R, Tremblay N, Dykes RW (1987) Acetylcholine permits long-term enhancement of neuronal responsiveness in cat primary somatosensory cortex. Neuroscience 22:75-81.
Mcthcratc R, Tremblay N, Dykes RW (1988a) The effects of acetylcholine on response properties of cat somatosensory cortical neurons. J Neurophysiol 59:1231-1252.

Metherate R, Tremblay N, Dykes RW (1988b) Transient and prolonged effects of acetylcholine on responsiveness of cat somatosensory cortical neurons. J Neurophysiol 59:1253-1276.

Nilsson OG, Björklund A (1992) Behavior-dependent changes in acetylcholine release in normal and graft-reinnervated hippocampus: evidence for host regulation of grafted cholinergic neurons. Neuroscience 49:33-44.

Nilsson OG, Shapiro ML, Gage FH, Olton DS, Björklund A (1987) Spatial learning and memory following fimbria-fornix transection and grafting of fetal septal neurons to the hippocampus. Exp Brain Res 67:195-215.

Paxinos G, Watson C (1982) The rat brain in stereotaxic coordinates. New York: Academic.

Rasmusson DD, Dykes RW (1988) Long-term enhancement of evoked potentials in cat somatosensory cortex produced by co-activation of the basal forebrain and cutaneous receptors. Exp Brain Res 70:276286.

Ridley RM, Thornley HD, Baker HF, Fine A (1991) Cholinergic neural transplants into hippocampus restore learning ability in monkeys with fornix transections. Exp Brain Res 83:533-538.

Ridley RM, Gribble S, Clark B, Baker HF, Fine A (1992) Restoration of learning ability in fornix-transected monkeys after fetal basal forebrain but not fetal hippocampal tissue transplantation. Neuroscience 48:779-792.

Rye DB, Wainer BH, Mesulam M-M, Mufson EJ, Saper CB (1984) Cortical projections arising from the basal forcbrain: a study of cholinergic and noncholinergic components employing combined retrograde tracing and immunohistochemical localization of choline acetyltransferase. Neuroscience 13:627-643.

Saper CB (1984) Organization of cerebral cortical afferent systems in the rat. II. Magnocellular basal nucleus. J Comp Neurol 222:313342.

Sato H, Hata Y, Masui H, Tsumoto T (1987) A functional role of cholinergic innervation to neurons in the cat visual cortex. J Neurophysiol 58:765-780.

Shapiro ML, Simon DK, Olton DS, Gage FH, Nilsson O, Björklund A (1989) Intrahippocampal grafts of fetal basal forebrain tissue alter place fields in the hippocampus of rats with fimbria-fornix lesions. Neuroscience 32:1-18.

Sillito $\Lambda \mathrm{M}$, Kemp JA (1983) Cholincrgic modulation of the functional organization of the cat visual cortex. Brain Res 289:143-155.

Sillito AM, Murphy PC (1987) The cholinergic modulation of cortical function. In: Cerebral cortex, Vol 6 (Jones EG, Peters A, eds), pp 161-185. New York: Plenum.

Stanfield BB, Cowen WM (1988) The development of the hippocampal region. In: Cerebral cortex, Vol 7 (Peters A, Jones EG, eds), pp 91131. New York: Plenum.

Stichel CC, Singer W (1987) Quantitative analysis of the choline acetyltransferase-immunoreactive axonal network in the cat primary visual cortex: I. Adult cats. J Comp Neurol 258:91-98.

Tommerdahl M, Raker R, Whitsel BL, Juliano SL (1985) A method for reconstructing patterns of somatosensory cerebral cortical activity. Biomed Sci Instrum 21:93-98.

Vanderwolf $\mathrm{CH}$, Fine $\Lambda$, Cooley RK (1990) Intracortical grafts of embryonic basal forebrain tissue restore low voltage fast activity in rats with basal forebrain lesions. Exp Brain Res 81:426-432.

Webster HH, Hanisch U-K, Dykes RW, Biesold D (1991) Basal forebrain lesions with or without reserpine injection inhibit cortical reorganization in rat hindpaw primary somatosensory cortex following sciatic nerve section. Somatosens Mot Res 8:327-346.

Wenk H, Bigl V, Meyer U (1980) Cholinergic projections from magnocellular nuclei of the basal forebrain to cortical areas in rats. Brain Res Rev 2:295-316.

Wong-Riley M (1979) Changes in the visual system of monocularly sutured or enucleated cats demonstrable with cytochrome oxidase histochemistry. Brain Res 171:11-28. 